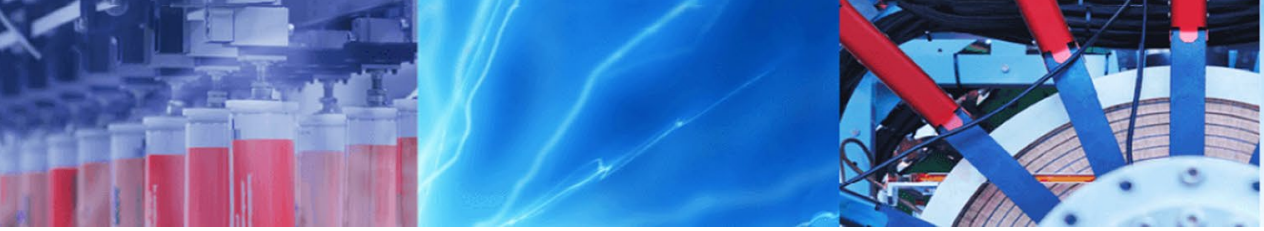

Research Article

\title{
Decoupled multicomponent potential theory of adsorption of gas mixtures
}

\author{
Raphaël Gervais Lavoie ${ }^{1,2} \cdot$ Jean Hamelin ${ }^{1,2} \cdot$ Pierre Bénard $^{1,2}$
}

Received: 11 June 2020 / Accepted: 6 November 2020 / Published online: 23 November 2020

(c) Springer Nature Switzerland AG 2020

\begin{abstract}
In this paper, we present a new version of the multicomponent potential theory of adsorption model. The proposed modification makes a clear distinction between adsorbent dependent parameters from adsorbate dependent ones. This leads to a better understanding of the physical significance of the parameters. The interdependence between pure isotherms is eliminated, which means that each component can be individually finely adjusted. This new approach was tested against 14 datasets for a total of 510 experimental mixture adsorption data of $\mathrm{CH}_{4}, \mathrm{CO}_{2}, \mathrm{~N}_{2}, \mathrm{H}_{2}, \mathrm{O}_{2}, \mathrm{H}_{2} \mathrm{~S}, \mathrm{C}_{2} \mathrm{H}_{6}, \mathrm{C}_{3}$ $\mathrm{H}_{6}$, and $\mathrm{C}_{3} \mathrm{H}_{8}$ on activated carbons, MOF, and zeolites. A slight improvement of $4.67 \%$ on excess adsorption predictions was found, leading to an overall average error of $6.97 \%$ for total excess adsorption and $15.30 \%$ for combined mixtures and components excess adsorption predictions.
\end{abstract}

Keywords Adsorption · Mixture adsorption · Multicomponent adsorption · Potential theory of adsorption · MPTA · Density functional theory

\section{Introduction}

In the standard definition of the Multicomponent Potential Theory of Adsorption model (MPTA), some fitting parameters are interdependent, which requires the simultaneous fitting of pure isotherms. This situation results from the choice of minimizing the number of adjustable parameters of the model. The proposed reinterpretation of the model eliminates this interdependence by introducing new adjustable parameters, specific to each gas component, which ultimately simplify the model's adjustment and understanding. Both approaches were tested against 14 different experimental datasets from the literature [1-13]. The datasets include 510 individual mixture adsorption measurements, in which 72 are ternary mixtures adsorption. The fluids considered are $\mathrm{CH}_{4}, \mathrm{CO}_{2}, \mathrm{~N}_{2}, \mathrm{H}_{2}, \mathrm{O}_{2}, \mathrm{H}_{2} \mathrm{~S}, \mathrm{C}_{2}$ $\mathrm{H}_{6}, \mathrm{C}_{3} \mathrm{H}_{6}$, and $\mathrm{C}_{3} \mathrm{H}_{8}$. The adsorbent materials are activated carbons (Filtrasorb-400, Norit-R1, AP-360, BPL), metalorganic frameworks (MOF-5, CuBTC), and zeolites (4A, 5A, $13 \mathrm{X}, \mathrm{ZSM}-5$, Mordenite). The experiments were performed both volumetrically and gravimetrically at temperatures ranging from 297 to $473 \mathrm{~K}$. The datasets were chosen based on the quality and availability of the experimental data and the wide range of adsorptive gases, type of material, and adsorption temperature.

Since there are many variables and symbols used in this paper, Table 1 regroups all of the definitions. Also, each time the superscript $i$ or $j$ is used, it refers to the particular mixture component.

\subsection{Pure gas MPTA model}

When talking about adsorption, it is useful to define the bulk phase as the region far from the adsorbent where the

$\triangle$ Raphaël Gervais Lavoie, raphael.gervaislavoie@uqtr.ca | Institut de recherche sur l'hydrogène, Université du Québec à Trois-Rivières, Trois-Rivières, Québec, Canada. ${ }^{2}$ Département de chimie, biochimie et physique, Université du Québec à Trois-Rivières, Trois-Rivières, Québec, Canada. 
Table 1 Symbols and definitions

\begin{tabular}{ll}
\hline Variable & Definition \\
\hline$\mu_{B}$ & Chemical potential of the bulk phase $(\mathrm{J} / \mathrm{mol})$ \\
$\mu_{\text {Ad }}$ & Chemical potential of the adsorbed phase $(\mathrm{J} / \mathrm{mol})$ \\
$\varepsilon$ & Adsorbent surface potential $(\mathrm{J} / \mathrm{mol})$ \\
$\rho_{B}$ & Fluid density in the bulk phase $(\mathrm{mol} / \mathrm{L})$ \\
$\rho_{\text {Ad }}$ & Fluid density in the adsorbed phase $(\mathrm{mol} / \mathrm{L})$ \\
$\varepsilon_{0}$ & Characteristic energy of adsorption $(\mathrm{J} / \mathrm{mol})$ \\
$z$ & Microporous volume $\left(\mathrm{cm}^{3} / \mathrm{g}\right)$ \\
$z_{0}$ & Limiting micropore volume $\left(\mathrm{cm}^{3} / \mathrm{g}\right)$ \\
$\beta$ & Heterogeneity parameter \\
$N_{\text {ex }}$ & Excess (Gibbs) adsorption $(\mathrm{mol} / \mathrm{kg})$ \\
$x_{B}$ & Bulk phase molar fraction $\left(\mathrm{mol}^{i} / \mathrm{mol}_{\text {Tot }}\right)$ \\
$x_{\text {Ad }}$ & Adsorbed phase molar fraction $\left(\mathrm{mol}^{i} / \mathrm{mol}_{\text {Tot }}\right)$ \\
$T$ & Fluid temperature (K) \\
$S_{i / j}$ & Selectivity of component $i$ over component $j$ \\
\hline
\end{tabular}

fluid is unaffected by the adsorbent material. Conversely, the adsorbed phase will represent the region near the surface where the fluid is significantly affected by the presence of the adsorbent material.

The potential theory of adsorption (PTA) is a two-parameter thermodynamic model developed by Shapiro and Stenby [14] based on the pore filling approach of Polanyi's theory of adsorption [15]. The PTA model was generalized to MPTA for gas mixtures adsorption by Shapiro, Stenby, and Monsalvo $[14,16]$. The MPTA model supposes that the fluid-surface interaction is entirely described by a local potential field $\varepsilon$, generated by the surface $[17,18]$. A common choice for this purpose is the Dubinin-Radushkevich-Astakhov [19-21] potential (DRA), given by

$\varepsilon(z)= \begin{cases}\varepsilon_{0}\left(\ln \frac{z_{0}}{z}\right)^{1 / \beta} & \text { if } 0 \leq z \leq z_{0} \\ 0 & \text { if } z>z_{0},\end{cases}$

where $\varepsilon_{0}$ and $z_{0}$ are the characteristic energy of adsorption and the limiting micropore volume, respectively. $\beta$ is a parameter which is usually interpreted as a quantification of the heterogeneity of the adsorbent $[22,23]$. Usually, for activated carbon, the parameter $\beta$ is set to 2 , while $\varepsilon_{0}$ and $z_{0}$ are determined by fitting the model to experimental data (see [24] for details). The ratio $z / z_{0}$ represents the fraction of the microporous volume associated with an energy $\varepsilon(z)$.

The MPTA model is defined by $[14,25]$

$\mu_{B}\left(T, \rho_{B}\right)=\mu_{\text {Ad }}\left(T, \rho_{\text {Ad }}\right)-\varepsilon$,

where $\mu_{B}$ and $\rho_{B}$ are, respectively, the chemical potentials and the fluid density in the bulk phase, while $\mu_{\mathrm{Ad}}$ and $\rho_{\mathrm{Ad}}$ are the local chemical potentials and fluid density in the adsorbed phase. The bulk phase properties are assumed to be constant while the adsorbed phase properties vary with position [14]. Using Eq. (2), the adsorbed phase's local thermodynamic properties are uniquely determined from properties of the bulk phase and the values of the parameter $z_{0}, \varepsilon_{0}$ and $\beta$ through the potential $\varepsilon$. Correspondance between gas pressure and density is carried out through an equation of state. The Nist REFPROP is used here for density and chemical potential calculations $[24,26]$. In the following, we will omit the temperature dependence since $T$ is assumed to be constant.

Equation (2) is inverted to obtain $\rho_{\mathrm{Ad}}(z)$ from the chemical potentials. The (Gibbs) excess adsorption $N_{\text {ex }}$ (which is what is experimentally measured) is then calculated from

$N_{\mathrm{ex}}\left(\rho_{B}\right)=\int_{0}^{z_{0}}\left(\rho_{\text {Ad }}(z)-\rho_{B}\right) d z$.

Optimal values for the fittings parameters are obtained by minimizing the difference $N_{\mathrm{ex}}\left(\rho_{B}\right)-N_{\mathrm{ex}}^{\text {exp }}\left(\rho_{B}\right)$ for pure gases isotherms. The fitting is performed by a Python implemented Levenberg-Marquardt algorithm [27].

\subsection{Gas mixtures}

For gas mixtures with $M$ components, the simplest approach is to consider that each fluid component $i$ is affected by its own surface potential

$\varepsilon^{i}(z)= \begin{cases}\varepsilon_{0}^{i}\left(\ln \frac{z_{0}}{z}\right)^{1 / \beta} & \text { if } 0 \leq z \leq z_{0}, \quad i=1 \ldots M, \\ 0 & \text { if } z>z_{0},\end{cases}$

where $\varepsilon_{0}^{i}$ refers to a given component. The parameters $z_{0}$ and $\beta$ are generally assumed to be common to all mixture components [28]. Equation (2) now becomes a non-linear coupled system of $M$ equations

$\mu_{B}^{i}\left(\rho_{B}, x_{B}^{i}\right)+\varepsilon^{i}(z)-\mu_{\text {Ad }}^{i}\left(\rho_{\text {Ad }}(z), x_{\text {Ad }}^{i}(z)\right)=0, \quad i=1 \ldots M$,

in which $x^{i}$ is the molar fraction of a component $i$ of the mixture. Due to the adsorbent material's selectivity, the local molar fraction $x_{A d}^{i}(z)$ will vary in the adsorbed phase, whereas the molar fraction of the bulk phase $x_{B}^{i}$ is constant. Here again, the mixture densities are obtained from pressure measurements, mixture molar fraction, and the REFPROP software.

Equations (5) are solved for $\rho_{\mathrm{Ad}}(z)$ and $x_{\mathrm{Ad}}^{i}(z)$. The excess (Gibbs) adsorption of each component in the mixture is obtained from

$N_{\mathrm{ex}}^{i}\left(\rho_{B}\right)=\int_{0}^{z_{0}}\left(\rho_{\mathrm{Ad}}(z) x_{\mathrm{Ad}}^{i}(z)-\rho_{B} x_{B}^{i}\right) d z, \quad i=1 \ldots M$. 
Finally, the total adsorbed amount is the sum of the contributions of each component

$N_{\mathrm{ex}}\left(\rho_{B}\right)=\sum_{i=1}^{M} N_{\mathrm{ex}}^{i}\left(\rho_{B}\right)$

A key feature of the MPTA model is that the fitting parameters $\varepsilon_{i}$ and $z_{0}$ (and possibly $\beta$ ) are solely obtained from pure gas adsorption isotherms in order to predict multicomponent adsorption $[14,16]$.

Up to this point, the described model corresponds to the conventional MPTA model. The next section describes the proposed decoupled MPTA model, starting with a conceptual justification in Sect. 2.1 followed by a formal definition in Sect. 2.2, and a discussion of both models in Sect. 2.3.

\section{Decoupled MPTA: independent $z_{0}$ and $\beta$ parameters}

\subsection{Conceptual justification of the new model}

Using unique values of $z_{0}$ and $\beta$ for all fluids components is generally justified by the fact that those parameters are mostly properties of the adsorbent material. Moreover, this allows the reduction of the fitting parameters to $M+1$ (or $M+2$ if $\beta$ is also fitted).

However, there are some disadvantages to this approach. Firstly, all the pure gases must be refitted each time that a single component is modified. For example:

- Let us consider a binary mixture of gas A and B. The model must be simultaneously fitted on pure isotherms for gas $A$ and $B$ to obtain $\varepsilon_{0^{\prime}}^{A}, \varepsilon_{0^{\prime}}^{B} z_{0}$, and $\beta$.

- Now, if a new mixture of gas $A$ and $C$ is considered, parameters $\varepsilon_{0}^{A}, z_{0}$, and $\beta$ cannot be reused.

- The model must be refit using the new $A$ and $C$ isotherms to obtain $\varepsilon_{0}^{\prime A}, \varepsilon_{0}^{C}, z_{0^{\prime}}^{\prime}$ and $\beta^{\prime}$.

Since $\varepsilon_{0}^{i}$ and $z_{0}$ change every time a component of the mixture is changed, the interpretation of those parameters as characteristic energy of adsorption of component $i$ and limiting micropore volume becomes less clear. Indeed, at least the characteristic energy of adsorption is expected to be constant for the pure adsorption of a pair adsorbate-adsorbent. This is not the case in the conventional MPTA approach.

Secondly, physically speaking, any interaction is characterized by its strength and its range, as so for the fluid-surface potential $\varepsilon$. For the sake of the discussion, let us consider the simple graphite adsorbent structure where the surface is essentially constituted of isotropic 2D carbon planes. In that case, the microporous volume $z$ is just a specific surface area times a distance to the surface. From the nearly crystalline structure of the graphite, we can infer that this specific surface area is constant, leaving $z$ being essentially a variable of the distance to the surface. This implies that $z_{0}$ will also be the product of the same characteristic surface times a characteristic distance to the surface. Any characteristic distance to a surface surely represents a range of interaction, and then, functionally speaking, this means that $z_{0}$ represents the range of the fluid-surface interaction. This leaves $\varepsilon_{0}$ representing the strength of the interaction.

For disorganized adsorbent structures, the situation is more complicated, but $z$ still can be interpreted as a measure of the distance to the surface time a specific surface. However, this time, the specific surface is given by some complicated geometrical average of the porous surface.

The upshot is that $z_{0}$ is linked to the range of the interaction, and then, it makes much more sense to consider different $z_{0}$ for different pure gases rather than the same $z_{0}$ for all gases.

Also, in the perspective of complex mixtures with many components, it will be even more challenging to fit all these pure isotherms simultaneously rather than fitting each component individually.

Finally, one of the far-reaching goals is to be able, under certain conditions, to extrapolate MPTA parameters from one adsorbent to another one. For instance, would it be possible to predict adsorption on one adsorbent considering another adsorbent's experimental dataset sharing similar properties? The first step in this direction is to separate the fluid-fluid part of the interaction from the fluid-surface part, and this is precisely what the new model does. Without this separation, any attempt to extrapolate from one adsorbent to another will suffer from excessive fluid-fluid interaction.

\subsection{Decoupled MPTA definition}

From all the considerations of Sect. 2.1, individual values of $z_{0}$ and $\beta$ can be introduced from minor modifications of the fluid-surface potential which now reads

$\varepsilon^{i}(z)= \begin{cases}\varepsilon_{0}^{i}\left(\ln \frac{z_{0}^{i}}{z}\right)^{1 / \beta^{i}} & \text { if } 0 \leq z \leq z_{0}^{i} \quad i=1 \ldots M . \\ 0 & \text { if } z>z_{0^{\prime}}^{i}\end{cases}$

Now, $\epsilon_{0}^{i}, z_{0}^{i}$ and $\beta^{i}$ are parameters specific to pure gas $i$. The modified potential (8) induces no modification to the system of equation (5).

For excess adsorption, the situation is more complicated. It was said earlier that the adsorbed phase is the 
region where the fluid is affected by the presence of the adsorbent surface. This definition now needs to be clarified and extended to the indirect effects of other gases components. Indeed, let us consider the region $z_{0}^{i}<z \leq z_{0}^{j}$. In that region, the surface potential $\varepsilon^{i}(z)=0$ since $z>z_{0^{\prime}}^{i}$ which seems to indicate that the gas $i$ is unaffected by the presence of the adsorbent. However, the component $j$ will be affected by the presence of the adsorbent in that region since $\varepsilon^{j}(z) \neq 0$ as $z \leq z_{0}^{j}$. However, the fact that the component $j$ is affected by the adsorbent will modify its local molar fraction $x_{\mathrm{Ad}}^{j}(z)$. Since $\sum_{i} x_{\mathrm{Ad}}^{i}=1$, local molar fractions are not independent and then, $x_{\mathrm{Ad}}^{i}$ will be affected indirectly by the adsorption of component $j$.

The easiest way to see this is by looking at the molar fraction of component $i$ in the range $z_{0}^{i}<z \leq z_{0}^{j}$, which would have been constant if component $i$ was not affected at all. Figure 1 shows this situation for a mixture of $72 \%$ $\mathrm{CH}_{4} / 28 \% \mathrm{CO}_{2}$ at bulk pressure of $8.3 \mathrm{MPa}$ and temperature of $318.2 \mathrm{~K}$ (experimental data were taken in [1]). In the region $z_{0}^{i}<z \leq z_{0}^{j}$ (the light gray area), we see that the molar fraction of $\mathrm{CH}_{4}$ vary with $z$ even if the surface potential $\varepsilon^{\mathrm{CH}_{4}}(z)$ vanish in that region. At $z=z_{0}^{i}$, the $\mathrm{CH}_{4}$ starts to interact with the surface through non-vanishing $\varepsilon^{\mathrm{CH}_{4}}(z)$, and we observe a change in the reads of the molar fraction. The sharp variation of the molar fraction at $z=z_{0}^{i}$ is obviously not physical. It came from the DRA potential, which is not smooth at $z=z_{0}^{i}$.

It is also interesting to take a look at the fluid density in that adsorbed phase region. Figure 2 shows the density profile of the mixture in the same conditions. This figure shows each component's contribution to the total density, such that the total fluid density is simply the sum of the individual component density. Here again, the sharp

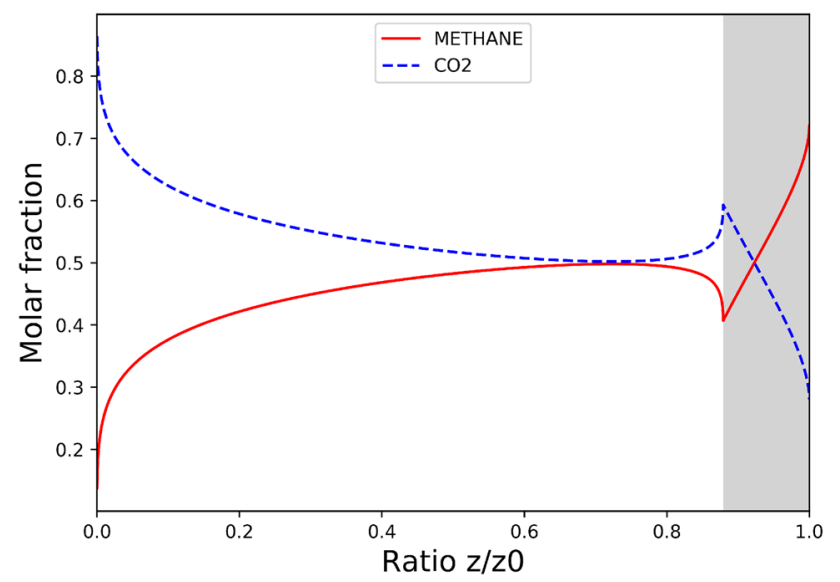

Fig. 1 Adsorbed phase molar fraction given by the new model for a $72 \% \mathrm{CH}_{4} / 28 \% \mathrm{CO}_{2}$ mixture (bulk pressure of $8.3 \mathrm{MPa}$ ) on Calgon F-400 activated carbon at $318.2 \mathrm{~K}$. The gray area represents the region where $\mathrm{CH}_{4}$ surface potential vanishes, but not the $\mathrm{CO}_{2}$ ones

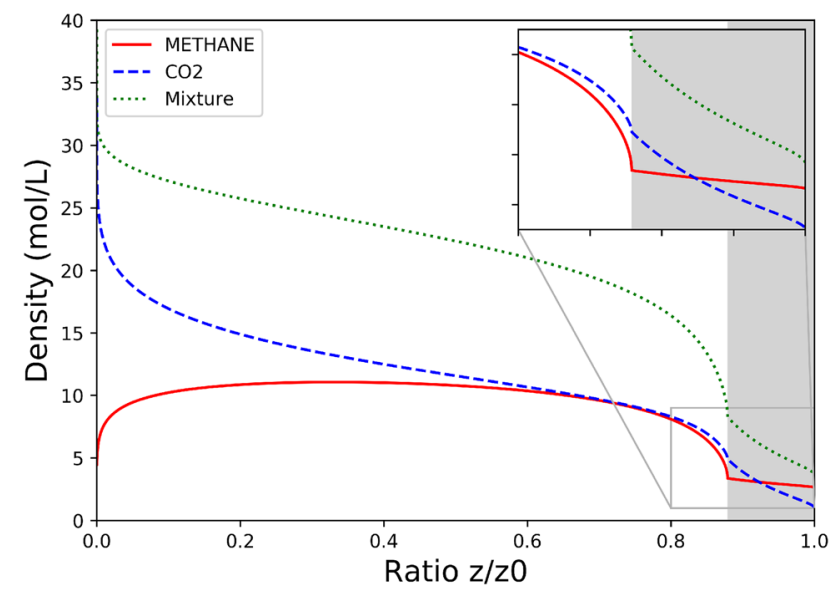

Fig. 2 Density profile of the adsorbed phase given by the new model for a $72 \% \mathrm{CH}_{4} / 28 \% \mathrm{CO}_{2}$ mixture (bulk pressure of $8.3 \mathrm{MPa}$ ) on Calgon F-400 activated carbon at $318.2 \mathrm{~K}$. The gray area represent the region were $\mathrm{CH}_{4}$ surface potential vanishes, but not the $\mathrm{CO}_{2}$ ones

variation of fluid density is not physical but is instead an artifact caused by the DRA potential.

The key point of this discussion is to realize that regardless of the component, the adsorbed phase's fluid properties differ from the ones of the bulk phase for $z<z_{0}^{\max }$. For $z \geq z_{0}^{\max }$, the integral vanishes, and then, the excess (Gibbs) adsorption for each component is

$N_{\mathrm{ex}}^{i}\left(\rho_{B}\right)=\int_{0}^{z_{0}^{\max }}\left(\rho_{\mathrm{Ad}}(z) x_{\mathrm{Ad}}^{i}(z)-\rho_{B} x_{B}^{i}\right) \mathrm{d} z, \quad i=1 \ldots M$,

where $z_{0}^{\text {max }}$ is simply the maximum value in $\left\{z_{0}^{i}\right\}$. The condition that $\varepsilon^{i}(z)=0$ if $z>z_{0}^{i}$ is required in the implementation since the integration now goes from 0 to $z_{0}^{\max }$ for all components.

Remark that the indirectly-interacting region of a component (the region $z_{0}^{i}<z \leq z_{0}^{j}$ for component $i$ ) will generate a negative contribution to the total component adsorption. Indeed, Figs. 1 and 2 show a decreasing molar fraction compared to the bulk phase, and a nearly constant component density which mean that $\rho_{\mathrm{Ad}}(z) x_{\mathrm{Ad}}^{i}(z)-\rho_{B} x_{B}^{i}<0$ in the indirectly-interacting region. The behavior of the component $i$ in the region $z_{0}^{i}<z \leq z_{0}^{j}$ represents a sort of emerging phenomena generated by the mixture's intrinsic nature.

Finally, with gas mixtures adsorption, it is quite useful to compare the adsorbent's components' affinity. This will be done by the use of the selectivity $S$ of a component over another one. The selectivity of component $i$ over component $j$ is defined as [6] 


$$
S_{i / j}=\frac{N_{\mathrm{ex}}^{i} x_{B}^{j}}{N_{\mathrm{ex}}^{j} x_{B}^{i}} .
$$

\subsection{Standard MPTA versus decoupled MPTA}

One of the main distinctions between standard and decoupled models is that in the later, the distinctive range of interaction of different gas species is taken into account through the introduction of individual $z_{0}^{i}$ parameters. As discussed in the previous section, the implementation of those individual $z_{0}^{i}$ parameters requires some precautions since non-interacting gases can still be indirectly affected by neighbor gases.

Decoupled model needs to be fitted on $3 M$ parameters $\left(\varepsilon_{0^{\prime}}^{i} z_{0^{\prime}}^{i}\right.$ and $\left.\beta^{i}\right)$ instead of $M+2$ parameters $\left(\varepsilon_{0^{\prime}}^{i} z_{0}\right.$, and $\left.\beta\right)$ for standard MPTA. However, the new form of the fluid-surface potential (8) decouples the fitting parameters for each component. In fact, the $3 M$ needed parameters split into $M$ individual three parameters fit. Once optimal $\epsilon_{0}, z_{0}$ and $\beta$ values have been found for a pure gas, there will be no need to refit the model on this gas. Those individual parameters encapsulate all the required information of a pure gas about the fluid-surface interaction, whatever the mixture considered. In other words, the decoupled model makes a clear cut between the fluid-surface interactions, which are governed by the fitting parameters $\left(\varepsilon_{0}, z_{0}\right.$, and $\beta$ ), and the fluid-fluid interactions, which are entirely governed by the EOS (the REFPROP in our case) as it should be. Moreover, it is easier to do $M$ individual three parameters fit than a single $M+2$ parameters fit.

Individual values of $z_{0}^{i}$ for the MPTA model have been previously used in the literature [29-31], where improvement of $3 \%$ and $2-3 \%$ compared to common $z_{0}$ value have been reported. We report a nearly $5 \%$ improvement in adsorption prediction using individual values of $z_{0}^{i}$, which confirm previously found results, although different adsorbent and adsorbate were used (liquid adsorbent were used in [30]). In [31], the differences between individual values of $z_{0}^{i}$ are treated as regions of the adsorbed phase that are only accessible to one component species. In this work, we looked at the differences between individual values of $z_{0}^{i}$ as differences in the range of gas-surface interaction. This means that all the space is accessible to all the component species. Moreover, in this work, the $\beta$ parameter of the DRA potential is treated as an individually adjustable parameter when $\beta$ is generally set to 2 in other work [29-31].

\subsection{Experimental uncertainties consideration}

To understand the limitation of the model, it is crucial to use accurate experimental data. Whether a volumetric or gravimetric method is used, the variables that are experimentally measured are the total excess adsorption $N_{\mathrm{ex}}^{T o t}$ (considering the pressure drop or increase of mass) and the bulk phase molar fraction $x_{B}$ (generally using gas chromatography). The "experimental" adsorbed phase molar fraction will be noted $\chi_{\mathrm{Ad}}^{i}$ and corresponds to the average proportion of component $i$ in the adsorbed phase. $\chi_{\mathrm{Ad}}^{i}$ is then calculated from the initial and equilibrium states, and the components adsorption are calculated from

$N_{\mathrm{ex}}^{i}=N_{\mathrm{ex}}^{\mathrm{Tot}} \chi_{\mathrm{Ad}}^{i, e x p}$.

The point here is that both $N_{\mathrm{ex}}^{\text {Tot }}$ and $\chi_{\mathrm{Ad}}^{i}$ are tainted by experimental uncertainties such that

$\left(\delta N_{\mathrm{ex}}^{i}\right)^{2}=\left(\delta N_{\mathrm{ex}}^{\mathrm{Tot}} \chi_{\mathrm{Ad}}^{i}\right)^{2}+\left(N_{\mathrm{ex}}^{\mathrm{Tot}} \delta \chi_{\mathrm{Ad}}^{i}\right)^{2}$.

Dividing both side by $\left(N_{\mathrm{ex}}^{i}\right)^{2}$, we obtain the relative error propagation equation

$\left(\frac{\delta N_{\mathrm{ex}}^{i}}{N_{\mathrm{ex}}^{i}}\right)^{2}=\left(\frac{\delta N_{\mathrm{ex}}^{\mathrm{Tot}} \chi_{\mathrm{Ad}}^{i}}{N_{\mathrm{ex}}^{i}}\right)^{2}+\left(\frac{N_{\mathrm{ex}}^{\mathrm{Tot}} \delta \chi_{\mathrm{Ad}}^{i}}{N_{\mathrm{ex}}^{i}}\right)^{2}$.

When considering a mixture of different component behavior, it is not uncommon to come across experimental conditions where $N_{\mathrm{ex}}^{i}$ is very small compared to $N_{\mathrm{ex}}^{\text {Tot }}$. Since $\delta \chi_{\mathrm{Ad}}^{i}$ is not necessarily that small, the second term of (13) can become quite large. Then, it is possible to end up with unacceptably large relative uncertainty. To illustrate this, let us consider a case encounter in the dataset where $N_{\text {ex }}^{T o t} \sim 6.2 \mathrm{mmol} / \mathrm{g}$ and $\delta \chi_{\mathrm{Ad}}^{i} \sim 0.002$. In that particular case, $N_{\text {ex }}^{i} \sim 0.02 \mathrm{mmol} / \mathrm{g}$, and then, the last term of (13) gives an unacceptable relative uncertainty of $\sim 60 \%$ on $N_{\text {ex }}^{i}$. From now on, the experimental data with relative uncertainty greater than $25 \%$ will be discarded from the fits. This $25 \%$ threshold, although arbitrary, represents a good balance between data accuracy and data retention for the fits.

For an experimental dataset with unknown experimental uncertainties, an experimental error of $1 \%$ on $N_{\text {ex }}^{\text {Tot }}$ and $1 \%$ on the smallest $x_{B}^{i}$ will be assumed to evaluate relative uncertainties. Those assumptions are fairly representative of the usual experimental uncertainties and were established from the experimental dataset with given experimental errors.

\section{Results}

Table 2 shows the considered datasets. It gives the mean pure fit error of both standard MPTA and the new implementation of the model, which will be labeled "new MPTA" 
Table 2 Pure gas mean fit for all the datasets considered

\begin{tabular}{lllll}
\hline Adsorbent & Adsorbate & $\mathrm{T}(\mathrm{K})$ & \multicolumn{2}{l}{ Mean pure fit error } \\
\cline { 5 - 5 } & & & Std MPTA & New MPTA $^{b}$ \\
\hline AC Calgon F-400 [1] & $\mathrm{CH}_{4} / \mathrm{N}_{2} / \mathrm{CO}_{2}$ & 318.2 & $2.82 \%$ & $1.91 \%$ \\
AC Norit R1 [2] & $\mathrm{CH}_{4} / \mathrm{N}_{2} / \mathrm{CO}_{2}$ & 298 & $3.17 \%$ & $1.22 \%$ \\
AC AP3-60 [3] & $\mathrm{N}_{2} / \mathrm{CO}_{2} / \mathrm{H}_{2}$ & 298 & $2.63 \%$ & $2.83 \%$ \\
AC BPL [4] & $\mathrm{CH}_{4} / \mathrm{C}_{2} \mathrm{H}_{6}$ & $297,301.4$ & $5.03 \%$ & $1.46 \%$ \\
MOF-5 [5, 6] & $\mathrm{CH}_{4} / \mathrm{N}_{2} / \mathrm{H}_{2} / \mathrm{CO}_{2}$ & 297 & $8.91 \%$ & $3.60 \%$ \\
CuBTC [6] & $\mathrm{N}_{2} / \mathrm{H}_{2} / \mathrm{CO}_{2}$ & 297 & $2.96 \%$ & $2.45 \%$ \\
Zeolite-4A [7] & $\mathrm{C}_{3} \mathrm{H}_{8} / \mathrm{C}_{3} \mathrm{H}_{6}$ & $423 / 473$ & $4.94 \%$ & $2.40 \%$ \\
Zeolite-5A [8] & $\mathrm{O}_{2} / \mathrm{N}_{2}$ & 296 & $2.82 \%$ & $1.31 \%$ \\
Zeolite-5A [9] & $\mathrm{CH}_{4} / \mathrm{N}_{2}$ & $303 / 323$ & $6.14 \%$ & $3.90 \%$ \\
Zeolite-13X [10] & $\mathrm{CH}_{4} / \mathrm{N}_{2}$ & $303 / 323$ & $7.04 \%$ & $3.36 \%$ \\
Zeolite-13X [11] & $\mathrm{CO}_{2} / \mathrm{N}_{2}$ & $298 / 318$ & $3.07 \%$ & $0.95 \%$ \\
Zeolite-ZSM-5 [11] & $\mathrm{CO}_{2} / \mathrm{N}_{2}$ & $298 / 318$ & $3.72 \%$ & $2.63 \%$ \\
Zeolite-NaX [12] & $\mathrm{CO}_{2} / \mathrm{CO}_{2}$ & $323 / 373$ & $5.46 \%$ & $2.24 \%$ \\
Zeolite H-Mordenite [13] & $\mathrm{CO}_{2} / \mathrm{H}_{2} \mathrm{~S} / \mathrm{C}_{3} \mathrm{H}_{8}$ & 303 & $7.25 \%$ & $3.00 \%$ \\
Average & & & $4.71 \%$ & $2.38 \%$ \\
\hline
\end{tabular}

a Std MPTA mean pure fit error refers to the mean absolute deviation between experimentally measured excess adsorptions and those computed by (3) using (2) and (1)

${ }^{b}$ New MPTA mean pure fit error refers to the mean absolute deviation between experimentally measured excess adsorptions and those computed by (3) using (2) and (8) with individual $z_{0^{\prime}}^{i} \varepsilon_{0}^{i}$ and $\beta^{i}$ parameters even if this is more of a reinterpretation of the MPTA rather than a new model.

In the following sections, the quality of the model predictions will be evaluated through the overall mean error (the average over all the $N_{\mathrm{ex}}^{i}$ or selectivity values) and the overall increased performance. Since the mixture system does not always have the same quantity of experimental data, the overall mean error is not necessarily the average of each system's mean error. The calculation is weighted to ensure an equal contribution for each experimental data in the overall mean error. The overall increased performance measures the accuracy of the new MPTA predictions compared to the standard MPTA model.

The MPTA model gives a point-to-point prediction of mixture adsorption based on temperature, pressure, and bulk phase molar fraction. Therefore, it is not usually possible to predict mixture adsorption between two experimental data points because the bulk phase molar fraction is not usually constant. This explains why the adsorption lines cannot be smoothed in Figs. 3, 4, 5 and 6, and why no isotherms are given. Constant bulk phase molar fraction solves this issue.

\subsection{AC Calgon F-400}

First, we consider the adsorption of $\mathrm{CH}_{4}, \mathrm{CO}_{2}, \mathrm{~N}_{2}$, and their binary mixtures on the bituminous-coal-based activated carbon Filtrasorb-400 12x40 mesh (Calgon Carbon Co.), which has a microporous volume of $0.4950 \mathrm{~cm}^{3} / \mathrm{g}$, and a BET surface of $850 \mathrm{~m}^{2} / \mathrm{g}$ [1]. Filtrasorb-400 possesses a high carbon content $(88.65 \%)$, which simplifies the characterization of the fluid-solid interactions. The material was regenerated under vacuum at $110^{\circ} \mathrm{C}$ for 2 days before being used. The measurements were performed volumetrically at $318.2 \mathrm{~K}$ with pressure up to $13.8 \mathrm{MPa}$. Adsorption of pure gases was carried out twice to guarantee reproducibility. Both runs were used to fit the MPTA model. Overall, the new model underestimates the mixture adsorption by $3.32 \%$, while the pure isotherms are overestimated by $2 \%$.

Table 3 gives the mean error between the prediction of both approaches, while Fig. 3 shows some of the new model results.

\subsection{AC Norit R1}

Binary and ternary mixtures of $\mathrm{CH}_{4}, \mathrm{~N}_{2}$, and $\mathrm{CO}_{2}$ are considered on activated carbon Norit R1 Extra which has a microporous volume of $0.3511 \mathrm{~cm}^{3} / \mathrm{g}$, and a BET surface of $1407.3 \mathrm{~m}^{2} / \mathrm{g}$ [2]. The measurements were performed gravimetrically at $298 \mathrm{~K}$ over a pressure ranging from $93 \mathrm{kPa}$ to $6.077 \mathrm{MPa}$. Overall, the new model underestimates the mixture's adsorption by $7.68 \%$, while the pure isotherms are underestimated by $0.82 \%$. 
Table 3 Comparison of standard and new MPTA models on Filtrasorb-400 at $318.2 \mathrm{~K}$ and pressure up to $13.8 \mathrm{MPa}$

\begin{tabular}{|c|c|c|c|c|c|}
\hline \multirow[t]{3}{*}{ System } & & \multicolumn{4}{|c|}{ Mean error (\%) } \\
\hline & & \multicolumn{2}{|c|}{ Std MPTA ${ }^{a}$} & \multicolumn{2}{|c|}{ New MPTA ${ }^{b}$} \\
\hline & & $\mathrm{N}_{\mathrm{ex}}^{i}$ & Select & $\mathrm{N}_{\mathrm{ex}}^{i}$ & Select \\
\hline \multirow[t]{3}{*}{$\mathrm{CH}_{4} / \mathrm{CO}_{2}$} & $\mathrm{CH}_{4}$ component & 25.37 & - & 14.03 & - \\
\hline & $\mathrm{CO}_{2}$ component & 6.50 & 52.59 & 7.88 & 27.47 \\
\hline & Mixture & 2.21 & - & 3.16 & - \\
\hline \multirow[t]{3}{*}{$\mathrm{CH}_{4} / \mathrm{N}_{2}$} & $\mathrm{CH}_{4}$ component & 3.30 & 6.94 & 7.83 & 11.82 \\
\hline & $\mathrm{N}_{2}$ component & 6.39 & - & 5.40 & - \\
\hline & Mixture & 3.36 & - & 4.13 & - \\
\hline \multirow[t]{3}{*}{$\mathrm{N}_{2} / \mathrm{CO}_{2}$} & $\mathrm{~N}_{2}$ component & 12.95 & - & 9.98 & - \\
\hline & $\mathrm{CO}_{2}$ component & 6.05 & 23.70 & 8.63 & 21.29 \\
\hline & Mixture & 1.49 & - & 3.30 & - \\
\hline \multicolumn{2}{|c|}{ Overall mean error } & 7.48 & 27.48 & 7.12 & 20.02 \\
\hline \multicolumn{2}{|c|}{ Overall increased performance } & - & - & 4.8 & 27.1 \\
\hline
\end{tabular}

113 experimental data points.

a Std MPTA mean pure fit error refers to the mean absolute deviation between experimentally measured excess adsorptions and those computed by (3) using (2) and (1)

${ }^{b}$ New MPTA mean pure fit error refers to the mean absolute deviation between experimentally measured excess adsorptions and those computed by (3) using (2) and (8) with individual $z_{0^{\prime}}^{i} \varepsilon_{0^{\prime}}^{i}$ and $\beta^{i}$ parameters

Table 4 gives the mean error between the prediction of both approaches, while Fig. 4 shows some selected results of the new model.

\subsection{AC AP3-60}

Binary mixtures of $\mathrm{CO}_{2}, \mathrm{~N}_{2}$, and $\mathrm{H}_{2}$ are considered on activated carbon Envirocarb AP3-60 (Chemviron Carbon) [3], which has a BET surface of $1000 \mathrm{~m}^{2} / \mathrm{g}$ (Chemviron Carbon). Envirocarb AP3-60 is a cylindrical 3-mm pellet activated carbon, and the material was regenerated under vacuum at $150^{\circ} \mathrm{C}$ for $8 \mathrm{~h}$ between experiments. The measurements were performed gravimetrically at $298 \mathrm{~K}$ over a pressure ranging from $400 \mathrm{kPa}$ to $11.86 \mathrm{MPa}$. Overall, the new model underestimates the mixture adsorption by $9.19 \%$, while the pure isotherms are underestimated by $1.22 \%$.

Table 5 gives the mean error between the prediction of both approaches.

\subsection{AC BPL}

Binary mixtures of $\mathrm{CO}_{2}$ and $\mathrm{C}_{2} \mathrm{H}_{6}$ are considered on activated carbon BPL $6 \times 16$ mesh (Calgon Carbon Co.) [4], which has a microporous volume of $0.630 \mathrm{~cm}^{3} / \mathrm{g}$ and a BET surface of $1200 \mathrm{~m}^{2} / \mathrm{g}$ [32]. Before entering the adsorption vessel, gasses were dried using packed columns of
$5 \mathrm{~A}$ molecular sieves. The measurements were performed volumetrically at $297 \mathrm{~K}$ and $301.4 \mathrm{~K}$ with pressure up to 2.5 $\mathrm{MPa}$. Overall, the new model underestimates the mixture adsorption by $9.76 \%$, while the pure isotherms are underestimated by $0.06 \%$.

Table 6 gives the mean error between the prediction of both approaches.

\subsection{MOF-5}

Binary mixtures of $\mathrm{CH}_{4}, \mathrm{~N}_{2}$, and $\mathrm{CO}_{2}$ and ternary mixture of $\mathrm{H}_{2}, \mathrm{CH}_{4}, \mathrm{~N}_{2}$, and $\mathrm{CO}_{2}$ are considered on metal-organic framework MOF-5 powder (Basolite $\mathrm{Z} 100-\mathrm{H}$ ), which has a microporous volume of $1.31 \mathrm{~cm}^{3} / \mathrm{g}$ and a BET surface of $3054 \mathrm{~m}^{2} / \mathrm{g}[5,6]$. The material was activated under vacuum at $125^{\circ} \mathrm{C}$ for at least $8 \mathrm{~h}$. The measurements were performed volumetrically at $297 \mathrm{~K}$ with pressure up to 1.5 MPa. Overall, the new model underestimates the mixture adsorption by $9.86 \%$, while the pure isotherms are underestimated by $1.60 \%$.

Table 7 gives the mean error between the prediction of both approaches, while Fig. 5 shows some selected results of the new model.

\subsection{CuBTC}

Ternary mixtures of $\mathrm{H}_{2}, \mathrm{~N}_{2}$, and $\mathrm{CO}_{2}$ are considered on metal-organic framework CuBTC (Basolite C300), which has a microporous volume of $0.66 \mathrm{~cm}^{3} / \mathrm{g}$ and a BET surface of $1556 \mathrm{~m}^{2} / \mathrm{g}$ [6]. The material was activated under vacuum at $125^{\circ} \mathrm{C}$ for at least $8 \mathrm{~h}$. The measurements were performed volumetrically at $297 \mathrm{~K}$ with pressure up to 1 $\mathrm{MPa}$. Overall, the new model underestimates the mixture adsorption by $31.93 \%$, while the pure isotherms are overestimated by $0.89 \%$.

Table 8 gives the mean error between the prediction of both approaches.

\subsection{Zeolite-4A}

Binary mixtures of $\mathrm{C}_{3} \mathrm{H}_{8}$ and $\mathrm{C}_{3} \mathrm{H}_{6}$ are considered on Zeolite-4A [7], which has a microporous volume of 0.2462 $\mathrm{cm}^{3} / \mathrm{g}$ and a BET surface of $559.13 \mathrm{~m}^{2} / \mathrm{g}$ [33]. The measurements were performed volumetrically at $423 \mathrm{~K}$ and $473 \mathrm{~K}$ over a pressure ranging from $85 \mathrm{kPa}$ to $145 \mathrm{kPa}$. Overall, the new model underestimates the mixture adsorption by $1.13 \%$, while the pure isotherms are overestimated by $0.32 \%$.

Table 9 gives the mean error between the prediction of both approaches. 

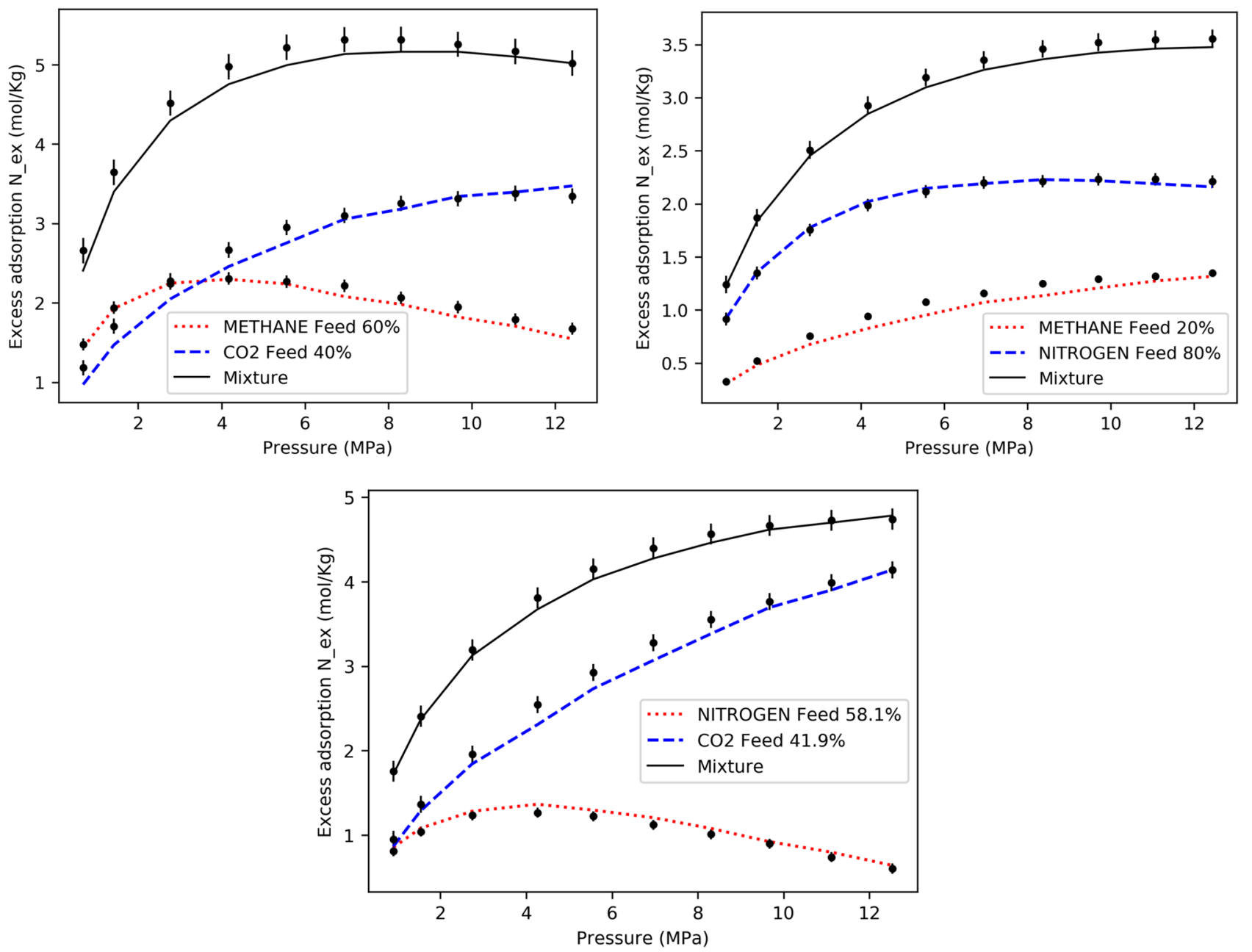

Fig. 3 New MPTA model selected examples of binary mixtures on Filtrasorb-400 at $318.2 \mathrm{~K}$ and pressure up to $13.8 \mathrm{MPa}$

\subsection{Zeolite-5A}

Binary mixtures of $\mathrm{O}_{2}$ and $\mathrm{N}_{2}$ are considered on a commercial Zeolite-5A $8 \times 10$ mesh (Tosoh Corporation) [8], which has a microporous volume of $0.198 \mathrm{~cm}^{3} / \mathrm{g}$ and a BET surface of $561.1 \mathrm{~m}^{2} / \mathrm{g}$ [34]. The material was regenerated under vacuum at $400{ }^{\circ} \mathrm{C}$. The measurements were performed volumetrically at $296 \mathrm{~K}$ over a pressure ranging from 23 to $921 \mathrm{kPa}$. Low-pressure measurements of pure gases were collected using a Micromeritics ASAP 2000. Overall, the new model underestimates the mixture adsorption by $4.68 \%$, while the pure isotherms are underestimated by $1.07 \%$.

Table 10 gives the mean error between the prediction of both approaches, while Fig. 6 shows some selected results of the new model.

Another experiment was carried out using $5 \mathrm{~A}$ Zeolite material. This time, binary mixtures of $\mathrm{CH}_{4}$ and $\mathrm{N}_{2}$ are considered on Zeolite-5A 3mm spherical particle (Zeochem $C_{0}$.), which has a reported BET surface of 457-600 $\mathrm{m}^{2} / \mathrm{g}$ [9]. The material was initially activated at $300^{\circ} \mathrm{C}$, and regenerated after each measurement under vacuum at $250{ }^{\circ} \mathrm{C}$ for $6 \mathrm{~h}$. The measurements were performed volumetrically at $303 \mathrm{~K}$ and $323 \mathrm{~K}$ over a pressure ranging from 98 to $916 \mathrm{kPa}$. Overall, the new model overestimates the mixture adsorption by $1.34 \%$, while the pure isotherms are underestimated by $3.03 \%$.

Table 11 gives the mean error between the prediction of both approaches.

\subsection{Zeolite-13X}

Binary mixtures of $\mathrm{CH}_{4}$ and $\mathrm{N}_{2}$ are considered on Zeolite13X (Zeochem Co.) [10], which has a microporous volume of $0.21 \mathrm{~cm}^{3} / \mathrm{g}$ and a BET surface of $164.3 \mathrm{~m}^{2} / \mathrm{g}$ [35]. The polar properties of the Zeolite-13X suggest a strong 
Table 4 Comparison of standard and new MPTA models on Norit$\mathrm{R} 1$ at $298 \mathrm{~K}$ and pressure up to $6 \mathrm{MPa}$

\begin{tabular}{|c|c|c|c|c|c|}
\hline \multirow[t]{3}{*}{ System } & & \multicolumn{4}{|c|}{ Mean error (\%) } \\
\hline & & \multicolumn{2}{|c|}{$\begin{array}{l}\text { Standard } \\
\text { MPTA }^{\text {a }}\end{array}$} & \multicolumn{2}{|c|}{ New MPTA ${ }^{b}$} \\
\hline & & $\mathrm{N}_{\mathrm{ex}}^{i}$ & Select & $\mathrm{N}_{\mathrm{ex}}^{i}$ & Select \\
\hline \multirow[t]{3}{*}{$\mathrm{CH}_{4} / \mathrm{CO}_{2}$} & $\mathrm{CH}_{4}$ component & 36.88 & - & 36.32 & - \\
\hline & $\mathrm{CO}_{2}$ component & 9.07 & 40.97 & 7.71 & 39.83 \\
\hline & Mixture & 5.79 & - & 5.66 & - \\
\hline \multirow[t]{3}{*}{$\mathrm{CH}_{4} / \mathrm{N}_{2}$} & $\mathrm{CH}_{4}$ component & 7.86 & 8.93 & 12.02 & 16.89 \\
\hline & $\mathrm{N}_{2}$ component & 7.00 & - & 6.13 & - \\
\hline & Mixture & 4.93 & - & 5.36 & - \\
\hline \multirow[t]{3}{*}{$\mathrm{CO}_{2} / \mathrm{N}_{2}$} & $\mathrm{CO}_{2}$ component & 4.26 & 27.76 & 4.40 & 24.72 \\
\hline & $\mathrm{N}_{2}$ component & 20.45 & - & 18.30 & - \\
\hline & Mixture & 3.50 & - & 5.27 & - \\
\hline \multirow[t]{4}{*}{$\mathrm{CH}_{4} / \mathrm{CO}_{2} / \mathrm{N}_{2}$} & $\mathrm{CH}_{4}$ component & 26.88 & $-^{c}$ & 26.42 & $-^{c}$ \\
\hline & $\mathrm{CO}_{2}$ component & 16.74 & $--^{\dagger}$ & 14.50 & $--^{\dagger}$ \\
\hline & $\mathrm{N}_{2}$ component & 57.04 & - & 58.87 & - \\
\hline & Mixture & 10.67 & - & 11.31 & - \\
\hline \multicolumn{2}{|c|}{ Overall mean error } & 19.09 & 25.39 & 19.18 & 27.79 \\
\hline \multicolumn{2}{|c|}{ Overall increased performance } & - & - & -0.47 & -9.45 \\
\hline
\end{tabular}

94 experimental data points

a Std MPTA mean pure fit error refers to the mean absolute deviation between experimentally measured excess adsorptions and those computed by (3) using (2) and (1)

b New MPTA mean pure fit error refers to the mean absolute deviation between experimentally measured excess adsorptions and those computed by (3) using (2) and (8) with individual $z_{0}^{i}, \epsilon_{0}^{i}$ and $\beta^{i}$ parameters

c Error on selectivity over $100 \%$ due to large error on the least adsorbed component

interaction with $\mathrm{CH}_{4}$, which one has higher polarizability than $\mathrm{N}_{2}$. The material was regenerated between each measurement under vacuum at $250^{\circ} \mathrm{C}$ for $6 \mathrm{~h}$. The measurements were performed volumetrically at $303 \mathrm{~K}$ and $323 \mathrm{~K}$ over a pressure ranging from 105 to $705 \mathrm{kPa}$. Overall, the new model overestimates the mixture adsorption by $5.95 \%$, while the pure isotherms are underestimated by $2.62 \%$.

Table 12 gives the mean error between the prediction of both approaches.

Another binary mixture adsorption experiment was carried out using the Zeolite-13X. This time, $\mathrm{CO}_{2}$ and $\mathrm{N}_{2}$ are considered on Zeolite-13X (Zeochem Co.) [11], which has a microporous volume of $0.21 \mathrm{~cm}^{3} / \mathrm{g}$ and a BET surface of $164.3 \mathrm{~m}^{2} / \mathrm{g}$ [35]. The adsorbent was regenerated between each new isotherm measurement under vacuum at $400{ }^{\circ} \mathrm{C}$ for $4 \mathrm{~h}$. The measurements were performed volumetrically at $298 \mathrm{~K}$ and $318 \mathrm{~K}$ over a pressure ranging from 115 to $1020 \mathrm{kPa}$. Overall, the new model underestimates the mixture adsorption by $16.65 \%$, while the pure isotherms are underestimated by $0.57 \%$.

Table 13 gives the mean error between the prediction of both approaches.

\subsection{Zeolite-ZSM-5}

Binary mixtures of $\mathrm{CO}_{2}$ and $\mathrm{N}_{2}$ are considered on ZeoliteZSM-5 (Zeochem Co.) [11], which has a microporous volume of $0.155 \mathrm{~cm}^{3} / \mathrm{g}$ and a BET surface from 264 to 312.4 $\mathrm{m}^{2} / \mathrm{g}$ [36]. The adsorbent was regenerated between each new isotherm measurement under vacuum at $400{ }^{\circ} \mathrm{C}$ for $4 \mathrm{~h}$. The measurements were performed volumetrically at $298 \mathrm{~K}$ and $318 \mathrm{~K}$ over a pressure ranging from 120 to 1010 $\mathrm{kPa}$. Overall, the new model underestimates the mixture adsorption by $7.51 \%$, while the pure isotherms are underestimated by $1.48 \%$.

Table 14 gives the mean error between the prediction of both approaches.

\subsection{Zeolite-NaX}

Binary mixtures of $\mathrm{CO}_{2}$ and $\mathrm{CO}$ are considered on Zeolite$\mathrm{NaX}$, which has a microporous volume of $0.283 \mathrm{~cm}^{3} / \mathrm{g}$ and a BET surface of $685 \mathrm{~m}^{2} / \mathrm{g}$ [12]. The measurements were performed volumetrically at $323 \mathrm{~K}$ and $373 \mathrm{~K}$ at a pressure of $100 \mathrm{kPa}$. Overall, the new model underestimates the mixture adsorption by $6.15 \%$, while the pure isotherms are overestimated by $0.65 \%$.

Table 15 gives the mean error between the prediction of both approaches.

\subsection{Zeolite H-Mordenite}

Binary and ternary mixtures adsorption of $\mathrm{CO}_{2}, \mathrm{H}_{2} \mathrm{~S}$, and $\mathrm{C}_{3}$ $\mathrm{H}_{8}$ are studied on hydrogen mordenite (Norton Company) [13], which has a BET surface of $400 \mathrm{~m}^{2} / \mathrm{g}$ [37]. The measurements were performed volumetrically at $303 \mathrm{~K}$ over a pressure ranging from 1 to $61 \mathrm{kPa}$. Overall, the new model underestimates the mixture adsorption by $23.88 \%$, while the pure isotherms are overestimated by $0.59 \%$.

Table 16 gives the mean error between the prediction of both approaches.

\section{Discussion}

Tables 17 and 18 synthesize all the results and presented them under different scope. First, Table 17 compares standard and new MPTA model's adsorption accuracy based on mixture order (pure, binary, ternary), and separates results for total mixture from results for mixture components. Surprisingly, standard MPTA performs slightly better than 

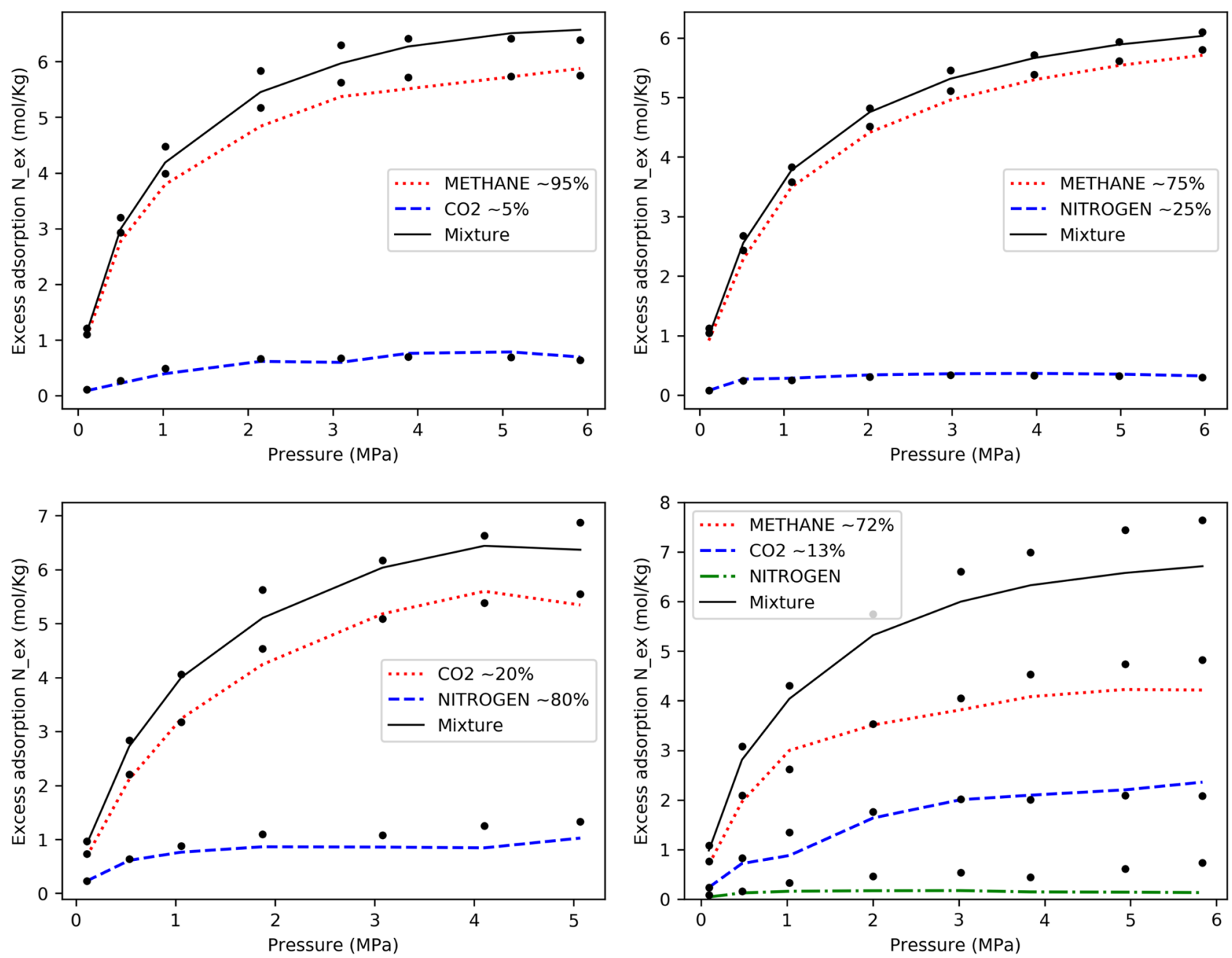

Fig. 4 New MPTA model selected examples of binary and ternary mixtures on Norit-R1 at $298 \mathrm{~K}$ and pressure up to $6 \mathrm{MPa}$

new MPTA for total binary mixture adsorption predictions. For all the cases except the total binary mixture, the new MPTA model performs better than the standard one, so globally, the new MPTA model is still the more accurate model. Moreover, even if the new MPTA model is slightly less accurate than standard MPTA for total binary mixture adsorption, both models are fairly accurate with around $6 \%$ accuracy.

Table 18 compares the binary mixture adsorption prediction accuracy of both models in the scope of adsorbent materials type. Here again, surprisingly, the standard MPTA model performs better than the new one for activated carbon total mixture adsorption. However, the new MPTA model still performs better for MOF, zeolite, and activated carbon component predictions. MOF is the adsorbent material with the best increases of performance with the new MPTA model (not a lot of data, however).

For all practical purposes, the most relevant information for gas mixture adsorption is the individual component adsorbed quantities rather than total mixture adsorption. 
Table 5 Comparison of standard and new MPTA models on activated carbon AP3-60 at $298 \mathrm{~K}$ and pressure up to $10.8 \mathrm{MPa}$

\begin{tabular}{|c|c|c|c|c|c|}
\hline \multirow[t]{3}{*}{ System } & & \multicolumn{4}{|c|}{ Mean error (\%) } \\
\hline & & \multicolumn{2}{|c|}{ Std MPTA $^{a}$} & \multicolumn{2}{|c|}{ New MPTA ${ }^{b}$} \\
\hline & & $\overline{\mathrm{N}_{\mathrm{ex}}^{i}}$ & Select & $\overline{\mathrm{N}_{\mathrm{ex}}^{i}}$ & Select \\
\hline \multirow[t]{3}{*}{$\mathrm{CO}_{2} / \mathrm{N}_{2}$} & $\mathrm{CO}_{2}$ component & 4.47 & - & 2.40 & - \\
\hline & $\mathrm{N}_{2}$ component & 33.45 & 62.57 & 27.91 & 52.62 \\
\hline & Mixture & 2.60 & - & 2.64 & - \\
\hline \multirow[t]{3}{*}{$\mathrm{CO}_{2} / \mathrm{H}_{2}$} & $\mathrm{CO}_{2}$ component & 3.38 & - & 4.00 & - \\
\hline & $\mathrm{H}_{2}$ component & 115.36 & $-^{c}$ & 108.44 & $-^{c}$ \\
\hline & Mixture & 13.30 & - & 12.47 & - \\
\hline \multicolumn{2}{|c|}{ Overall mean error } & 34.10 & 62.57 & 31.68 & 52.62 \\
\hline \multicolumn{2}{|c|}{ Overall increased performance } & - & - & 7.10 & 15.90 \\
\hline
\end{tabular}

40 experimental data points

a Std MPTA mean pure fit error refers to the mean absolute deviation between experimentally measured excess adsorptions and those computed by (3) using (2) and (1)

b New MPTA mean pure fit error refers to the mean absolute deviation between experimentally measured excess adsorptions and those computed by (3) using (2) and (8) with individual $z_{0}^{i}, \epsilon_{0}^{i}$ and $\beta^{i}$ parameters

c Error on selectivity over $100 \%$ due to large error on the least adsorbed component

Table 6 Comparison of standard and new MPTA models on activated carbon BPL at $297 \mathrm{~K}$ and $301.4 \mathrm{~K}$ and pressure up to $2.5 \mathrm{MPa}$

\begin{tabular}{|c|c|c|c|c|c|}
\hline \multirow[t]{3}{*}{ System } & & \multicolumn{4}{|c|}{ Mean error (\%) } \\
\hline & & \multicolumn{2}{|c|}{ Std MPTA ${ }^{a}$} & \multicolumn{2}{|c|}{ New MPTA ${ }^{b}$} \\
\hline & & $\mathrm{N}_{\mathrm{ex}}^{i}$ & Select & $\mathrm{N}_{\mathrm{ex}}^{i}$ & Select \\
\hline \multirow[t]{3}{*}{$\mathrm{CH}_{4} / \mathrm{C}_{2} \mathrm{H}_{6} 297 \mathrm{~K}$} & $\mathrm{CH}_{4}$ component & 13.57 & - & 12.88 & - \\
\hline & $\mathrm{C}_{2} \mathrm{H}_{6}$ component & 12.98 & 20.92 & 15.16 & 20.16 \\
\hline & Mixture & 9.04 & - & 9.64 & - \\
\hline \multirow[t]{3}{*}{$\mathrm{CH}_{4} / \mathrm{C}_{2} \mathrm{H}_{6} 301.4 \mathrm{~K}$} & $\mathrm{CH}_{4}$ component & 24.62 & - & 23.72 & - \\
\hline & $\mathrm{C}_{2} \mathrm{H}_{6}$ component & 12.96 & 45.01 & 13.14 & 49.26 \\
\hline & Mixture & 6.50 & - & 6.56 & - \\
\hline \multicolumn{2}{|l|}{ Overall mean error } & 13.43 & 34.30 & 13.62 & 36.33 \\
\hline \multicolumn{2}{|c|}{ Overall increased performance } & - & - & -1.41 & -5.92 \\
\hline
\end{tabular}

54 experimental data points

a Std MPTA mean pure fit error refers to the mean absolute deviation between experimentally measured excess adsorptions and those computed by (3) using (2) and (1)

b New MPTA mean pure fit error refers to the mean absolute deviation between experimentally measured excess adsorptions and those computed by (3) using (2) and (8) with individual $z_{0}^{i}, \epsilon_{0}^{i}$ and $\beta^{i}$ parameters
Table 7 Comparison of standard and new MPTA models on MOF-5 at $297 \mathrm{~K}$ and pressure from 0 to $1510 \mathrm{kPa}$

\begin{tabular}{|c|c|c|c|c|c|}
\hline \multirow[t]{3}{*}{ System } & & \multicolumn{4}{|c|}{ Mean error (\%) } \\
\hline & & \multicolumn{2}{|c|}{ Std MPTA ${ }^{a}$} & \multicolumn{2}{|c|}{ New MPTA $^{b}$} \\
\hline & & $\mathrm{N}_{\mathrm{ex}}^{i}$ & Select & $\overline{\mathrm{N}_{\mathrm{ex}}^{i}}$ & Select \\
\hline \multirow[t]{3}{*}{$\mathrm{CH}_{4} / \mathrm{CO}_{2}$} & $\mathrm{CH}_{4}$ component & 23.59 & - & 17.86 & - \\
\hline & $\mathrm{CO}_{2}$ component & 7.25 & 39.64 & 6.67 & 29.06 \\
\hline & Mixture & 5.56 & - & 4.10 & - \\
\hline \multirow[t]{3}{*}{$\mathrm{CH}_{4} / \mathrm{N}_{2}$} & $\mathrm{CH}_{4}$ component & 3.96 & 12.76 & 3.87 & 3.96 \\
\hline & $\mathrm{N}_{2}$ component & 10.04 & - & 6.09 & - \\
\hline & Mixture & 4.48 & - & 3.97 & - \\
\hline \multirow[t]{3}{*}{$\mathrm{CO}_{2} / \mathrm{N}_{2}$} & $\mathrm{CO}_{2}$ component & 5.50 & 47.77 & 5.22 & 33.36 \\
\hline & $\mathrm{N}_{2}$ component & 32.83 & - & 25.90 & - \\
\hline & Mixture & 7.75 & - & 7.26 & - \\
\hline \multirow[t]{4}{*}{$\mathrm{N}_{2} / \mathrm{CH}_{4} / \mathrm{CO}_{2}$} & $\mathrm{~N}_{2}$ component & 28.99 & - & 20.32 & - \\
\hline & $\mathrm{CH}_{4}$ component & 22.21 & $10.78^{c}$ & 15.79 & $10.54^{c}$ \\
\hline & $\mathrm{CO}_{2}$ component & 16.36 & $38.71^{\mathrm{c}}$ & 15.83 & $29.81^{c}$ \\
\hline & Mixture & 13.44 & - & 10.58 & - \\
\hline \multirow[t]{4}{*}{$\mathrm{H}_{2} / \mathrm{CH}_{4} / \mathrm{CO}_{2}$} & $\mathrm{H}_{2}$ component & 7.28 & - & 17.09 & - \\
\hline & $\mathrm{CH}_{4}$ component & 18.77 & $14.16^{c}$ & 13.18 & $7.93^{c}$ \\
\hline & $\mathrm{CO}_{2}$ component & 25.64 & $33.70^{c}$ & 12.12 & $30.36^{c}$ \\
\hline & Mixture & 21.20 & - & 9.07 & - \\
\hline \multirow[t]{4}{*}{$\mathrm{H}_{2} / \mathrm{N}_{2} / \mathrm{CO}_{2}$} & $\mathrm{H}_{2}$ component & 19.29 & - & 26.53 & - \\
\hline & $\mathrm{N}_{2}$ component & 16.72 & $15.13^{c}$ & 5.88 & $29.54^{c}$ \\
\hline & $\mathrm{CO}_{2}$ component & 19.64 & $37.71^{c}$ & 12.05 & $39.66^{c}$ \\
\hline & Mixture & 13.64 & - & 8.52 & - \\
\hline \multicolumn{2}{|c|}{ Overall mean error } & 16.43 & 27.64 & 12.61 & 21.88 \\
\hline \multicolumn{2}{|c|}{ Overall increased performance } & - & - & 23.25 & 20.84 \\
\hline
\end{tabular}

40 experimental data points.

a Std MPTA mean pure fit error refers to the mean absolute deviation between experimentally measured excess adsorptions and those computed by (3) using (2) and (1)

b New MPTA mean pure fit error refers to the mean absolute deviation between experimentally measured excess adsorptions and those computed by (3) using (2) and (8) with individual $z_{0}^{i}, \epsilon_{0}^{i}$ and $\beta^{i}$ parameters

c Represent the adsorption selectivity of the component compared to the first component 


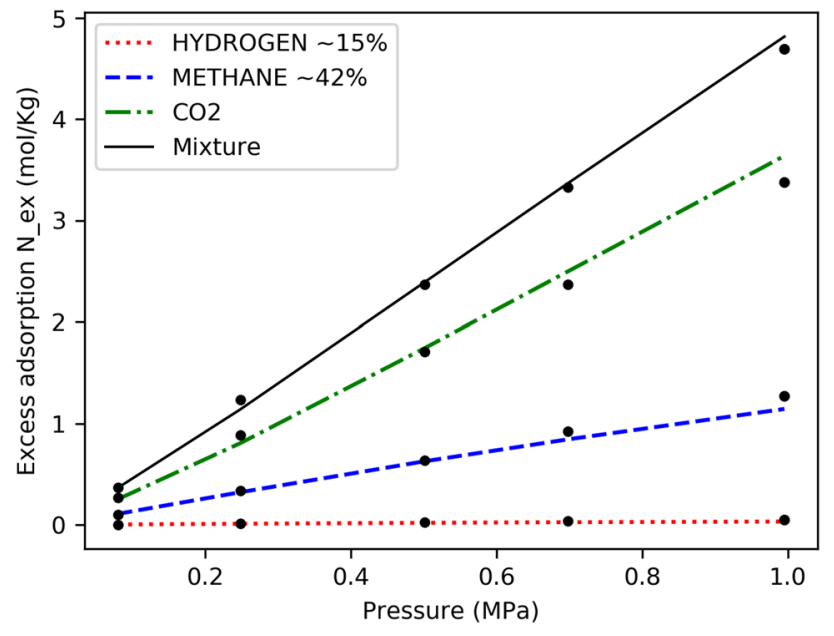

Fig. 5 New MPTA model selected examples of ternary mixture on MOF-5 at $297 \mathrm{~K}$ and pressure up to $1510 \mathrm{kPa}$

Table 8 Comparison of standard and new MPTA models on CuBTC at $297 \mathrm{~K}$ and pressure from 0 to $1 \mathrm{MPa}$

\begin{tabular}{|c|c|c|c|c|c|}
\hline \multirow[t]{3}{*}{ System } & & \multicolumn{4}{|c|}{ Mean error (\%) } \\
\hline & & \multicolumn{2}{|c|}{ Std MPTA ${ }^{a}$} & \multicolumn{2}{|c|}{ New MPTA ${ }^{b}$} \\
\hline & & $\mathrm{N}_{\mathrm{ex}}^{i}$ & Select & $\mathrm{N}_{\mathrm{ex}}^{i}$ & Select \\
\hline \multirow[t]{4}{*}{$\mathrm{H}_{2} / \mathrm{N}_{2} / \mathrm{CO}_{2}$} & $\mathrm{H}_{2}$ component & 42.49 & - & 35.14 & - \\
\hline & $\mathrm{N}_{2}$ component & 22.08 & $38.92^{c}$ & 28.66 & $11.80^{c}$ \\
\hline & $\mathrm{CO}_{2}$ component & 3.93 & $83.67^{c}$ & 4.18 & $63.18^{c}$ \\
\hline & Mixture & 2.90 & - & 2.10 & - \\
\hline \multicolumn{2}{|c|}{ Overall mean error } & 17.85 & 61.30 & 17.52 & 37.49 \\
\hline \multicolumn{2}{|c|}{ Overall increased performance } & - & - & 1.85 & 38.84 \\
\hline
\end{tabular}

Three experimental data points.

a Std MPTA mean pure fit error refers to the mean absolute deviation between experimentally measured excess adsorptions and those computed by (3) using (2) and (1)

b New MPTA mean pure fit error refers to the mean absolute deviation between experimentally measured excess adsorptions and those computed by (3) using (2) and (8) with individual $z_{0}^{i} \epsilon_{0}^{i}$ and $\beta^{i}$ parameters

c Represent the adsorption selectivity of the component compared to the first component
Table 9 Comparison of standard and new MPTA models on $4 \mathrm{~A}$-Zeolite at $423 \mathrm{~K}$ and $473 \mathrm{~K}$ and pressure close to $100 \mathrm{kPa}$

\begin{tabular}{|c|c|c|c|c|c|}
\hline \multirow[t]{3}{*}{ System } & & \multicolumn{4}{|c|}{ Mean error (\%) } \\
\hline & & \multicolumn{2}{|c|}{ Std MPTA ${ }^{a}$} & \multicolumn{2}{|c|}{ New MPTA ${ }^{b}$} \\
\hline & & $\mathrm{N}_{\mathrm{ex}}^{i}$ & Select & $\mathrm{N}_{\mathrm{ex}}^{i}$ & Selec \\
\hline \multirow[t]{3}{*}{$\mathrm{C}_{3} \mathrm{H}_{8} / \mathrm{C}_{3} \mathrm{H}_{6} 423 \mathrm{~K}$} & $\mathrm{C}_{3} \mathrm{H}_{8}$ component & 18.65 & - & 18.46 & - \\
\hline & $\mathrm{C}_{3} \mathrm{H}_{6}$ component & 4.03 & 32.26 & 3.80 & 30.59 \\
\hline & Mixture & 2.89 & - & 2.94 & - \\
\hline \multirow[t]{3}{*}{$\mathrm{C}_{3} \mathrm{H}_{8} / \mathrm{C}_{3} \mathrm{H}_{6} 473 \mathrm{~K}$} & $\mathrm{C}_{3} \mathrm{H}_{8}$ component & 14.72 & - & 13.56 & - \\
\hline & $\mathrm{C}_{3} \mathrm{H}_{6}$ component & 2.64 & 15.80 & 5.86 & 12.15 \\
\hline & Mixture & 3.76 & - & 3.40 & - \\
\hline \multicolumn{2}{|c|}{ Overall mean error } & 7.84 & 24.66 & 8.03 & 22.08 \\
\hline \multicolumn{2}{|c|}{ Overall increased performance } & - & - & -2.42 & 10.46 \\
\hline
\end{tabular}

13 experimental data points

a Std MPTA mean pure fit error refers to the mean absolute deviation between experimentally measured excess adsorptions and those computed by (3) using (2) and (1)

b New MPTA mean pure fit error refers to the mean absolute deviation between experimentally measured excess adsorptions and those computed by (3) using (2) and (8) with individual $z_{0}^{i}, \epsilon_{0}^{i}$ and $\beta^{i}$ parameters

The new MPTA model performs better than the standard ones for both binary and ternary components adsorption with an average accuracy of $15.77 \%$ and $34.46 \%$, respectively.

Tables 19 and 20 give a comparison for the fitting parameter between the new and standard MPTA model for $\mathrm{N}_{2} / \mathrm{CO}_{2}$ and $\mathrm{CH}_{4} / \mathrm{N}_{2}$ mixture on activated carbon, MOF, and zeolite. In both cases, the standard MPTA parameters are largely dominated by the most adsorbed component $\left(\mathrm{CO}_{2}\right.$ and $\mathrm{CH}_{4}$, respectively). Consequently, the $\varepsilon_{0}$ parameters of the least absorbed component differ substantially from the new MPTA model, where the components are individually fitted. 
Table 10 Comparison of standard and new MPTA models on 5 A-Zeolite at $296 \mathrm{~K}$ and pressure from 23 to 921 $\mathrm{kPa}$

\begin{tabular}{|c|c|c|c|c|c|}
\hline \multirow[t]{3}{*}{ System } & & \multicolumn{4}{|c|}{ Mean error (\%) } \\
\hline & & \multicolumn{2}{|c|}{ Std MPTA ${ }^{a}$} & \multicolumn{2}{|c|}{ New MPTA ${ }^{b}$} \\
\hline & & $\mathrm{N}_{\mathrm{ex}}^{i}$ & Select & $\mathrm{N}_{\mathrm{ex}}^{i}$ & Select \\
\hline \multirow[t]{3}{*}{$\mathrm{O}_{2} / \mathrm{N}_{2}$ open system } & $\mathrm{O}_{2}$ component & 24.41 & - & 21.51 & - \\
\hline & $\mathrm{N}_{2}$ component & 4.48 & 40.41 & 2.89 & 33.28 \\
\hline & Mixture & 2.39 & - & 1.62 & - \\
\hline \multirow[t]{3}{*}{$\mathrm{O}_{2} / \mathrm{N}_{2}$ closed system } & $\mathrm{O}_{2}$ component & 17.98 & - & 14.69 & - \\
\hline & $\mathrm{N}_{2}$ component & 13.70 & 36.10 & 10.56 & 26.00 \\
\hline & Mixture & 11.98 & - & 9.27 & - \\
\hline Overall mean error & & 11.61 & 39.18 & 9.48 & 31.20 \\
\hline Overall increased performance & & - & - & 18.3 & 20.3 \\
\hline
\end{tabular}

21 experimental data points

a Std MPTA mean pure fit error refers to the mean absolute deviation between experimentally measured excess adsorptions and those computed by (3) using (2) and (1)

${ }^{b}$ New MPTA mean pure fit error refers to the mean absolute deviation between experimentally measured excess adsorptions and those computed by (3) using (2) and (8) with individual $z_{0}^{i}, \epsilon_{0}^{i}$ and $\beta^{i}$ parameters
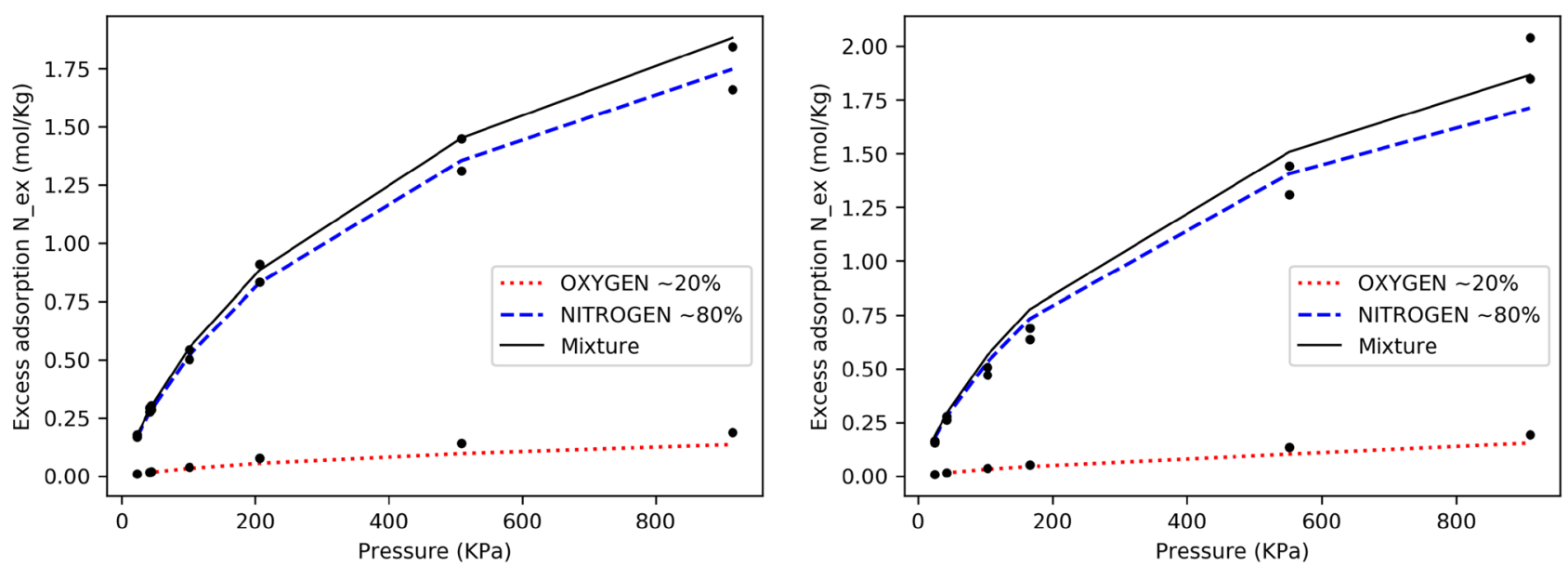

Fig. 6 Chosen examples of the new MPTA model for binary mixtures on Zeolite-5A at $296 \mathrm{~K}$ and pressure up to $921 \mathrm{kPa}$ 
Table 11 Comparison of standard and new MPTA models on Zeolite-5A at $303 \mathrm{~K}$ and $323 \mathrm{~K}$, and pressure from 98 to $916 \mathrm{kPa}$

\begin{tabular}{|c|c|c|c|c|c|}
\hline \multirow[t]{3}{*}{ System } & & \multicolumn{4}{|c|}{ Mean error (\%) } \\
\hline & & \multicolumn{2}{|c|}{ Std MPTA } & \multicolumn{2}{|c|}{ New MPTA ${ }^{b}$} \\
\hline & & $\mathrm{N}_{\mathrm{ex}}^{i}$ & Select & $\mathrm{N}_{\mathrm{ex}}^{i}$ & Select \\
\hline \multirow[t]{3}{*}{$\mathrm{CH}_{4} / \mathrm{N}_{2} 303 \mathrm{~K}$} & $\mathrm{CH}_{4}$ component & 6.00 & - & 9.32 & - \\
\hline & $\mathrm{N}_{2}$ component & 6.57 & 6.22 & 5.21 & 13.61 \\
\hline & Mixture & 5.86 & - & 5.81 & - \\
\hline \multirow[t]{3}{*}{$\mathrm{CH}_{4} / \mathrm{N}_{2} 323 \mathrm{~K}$} & $\mathrm{CH}_{4}$ component & 4.11 & - & 3.97 & - \\
\hline & $\mathrm{N}_{2}$ component & 5.12 & 4.24 & 8.37 & 9.58 \\
\hline & Mixture & 3.99 & - & 3.77 & - \\
\hline \multicolumn{2}{|c|}{ Overall mean error } & 5.61 & 5.61 & 6.35 & 12.37 \\
\hline \multicolumn{2}{|c|}{ Overall increased performance } & - & - & -13.19 & -120.50 \\
\hline
\end{tabular}

26 experimental data points

${ }^{\text {a }}$ Std MPTA mean pure fit error refers to the mean absolute deviation between experimentally measured excess adsorptions and those computed by (3) using (2) and (1)

b New MPTA mean pure fit error refers to the mean absolute deviation between experimentally measured excess adsorptions and those computed by (3) using (2) and (8) with individual $z_{0}^{i}, \epsilon_{0}^{i}$ and $\beta^{i}$ parameters

Table 12 Comparison of standard and new MPTA models on Zeolite- $13 \mathrm{X}$ at $303 \mathrm{~K}$ and $323 \mathrm{~K}$, and pressure up to $700 \mathrm{kPa}$

\begin{tabular}{|c|c|c|c|c|c|}
\hline \multirow[t]{3}{*}{ System } & & \multicolumn{4}{|c|}{ Mean error (\%) } \\
\hline & & \multicolumn{2}{|c|}{ Std MPTA ${ }^{a}$} & \multicolumn{2}{|c|}{ New MPTA ${ }^{\mathrm{b}}$} \\
\hline & & $\mathrm{N}_{\mathrm{ex}}^{i}$ & Select & $\mathrm{N}_{\mathrm{ex}}^{i}$ & Select \\
\hline \multirow[t]{3}{*}{$\mathrm{CH}_{4} / \mathrm{N}_{2} 303 \mathrm{~K}$} & $\mathrm{CH}_{4}$ component & 7.87 & - & 7.99 & - \\
\hline & $\mathrm{N}_{2}$ component & 6.06 & 14.31 & 3.37 & 9.52 \\
\hline & Mixture & 6.20 & - & 6.20 & - \\
\hline \multirow[t]{3}{*}{$\mathrm{CH}_{4} / \mathrm{N}_{2} 323 \mathrm{~K}$} & $\mathrm{CH}_{4}$ component & 13.11 & - & 8.68 & - \\
\hline & $\mathrm{N}_{2}$ component & 5.30 & 17.39 & 5.64 & 10.32 \\
\hline & Mixture & 9.45 & - & 8.89 & - \\
\hline \multicolumn{2}{|c|}{ Overall mean error } & 7.88 & 15.71 & 6.71 & 9.88 \\
\hline \multicolumn{2}{|c|}{ Overall increased performance } & - & - & 14.85 & 37.11 \\
\hline
\end{tabular}

33 experimental data points

a Std MPTA mean pure fit error refers to the mean absolute deviation between experimentally measured excess adsorptions and those computed by (3) using (2) and (1)

b New MPTA mean pure fit error refers to the mean absolute deviation between experimentally measured excess adsorptions and those computed by (3) using (2) and (8) with individual $z_{0}^{i}, \epsilon_{0}^{i}$ and $\beta^{i}$ parameters
Table 13 Comparison of standard and new MPTA models on Zeolite- $13 \mathrm{X}$ at $298 \mathrm{~K}$ and $318 \mathrm{~K}$, and pressure up to $1 \mathrm{MPa}$

\begin{tabular}{|c|c|c|c|c|c|}
\hline \multirow[t]{3}{*}{ System } & & \multicolumn{4}{|c|}{ Mean error (\%) } \\
\hline & & \multicolumn{2}{|c|}{ Std MPTA ${ }^{a}$} & \multicolumn{2}{|c|}{ New MPTA ${ }^{b}$} \\
\hline & & $\mathrm{N}_{\mathrm{ex}}^{i}$ & Select & $\mathrm{N}_{\mathrm{ex}}^{i}$ & Select \\
\hline \multirow[t]{3}{*}{$\mathrm{CO}_{2} / \mathrm{N}_{2} 298 \mathrm{~K}$} & $\mathrm{CO}_{2}$ component & 5.93 & - & 4.56 & - \\
\hline & $\mathrm{N}_{2}$ component & 58.20 & $--^{\dagger}$ & 53.12 & $--^{\dagger}$ \\
\hline & Mixture & 3.35 & - & 2.24 & - \\
\hline \multirow[t]{3}{*}{$\mathrm{CO}_{2} / \mathrm{N}_{2} 318 \mathrm{~K}$} & $\mathrm{CO}_{2}$ component & 6.46 & - & 6.07 & - \\
\hline & $\mathrm{N}_{2}$ component & 59.97 & $-^{c}$ & 49.07 & $-^{c}$ \\
\hline & Mixture & 4.15 & - & 4.16 & - \\
\hline \multicolumn{2}{|c|}{ Overall mean error } & 22.96 & - & 19.88 & - \\
\hline \multicolumn{2}{|c|}{ Overall increased performance } & - & - & 13.41 & - \\
\hline
\end{tabular}

11 experimental data points.

a Std MPTA mean pure fit error refers to the mean absolute deviation between experimentally measured excess adsorptions and those computed by (3) using (2) and (1)

b New MPTA mean pure fit error refers to the mean absolute deviation between experimentally measured excess adsorptions and those computed by (3) using (2) and (8) with individual $z_{0}^{i} \epsilon_{0}^{i}$ and $\beta^{i}$ parameters

c Error on selectivity over $100 \%$ due to large error on the least adsorbed component

Table 14 Comparison of standard and new MPTA models on Zeolite-ZSM-5 at $298 \mathrm{~K}$ and $318 \mathrm{~K}$, and pressure up to $1 \mathrm{MPa}$

\begin{tabular}{|c|c|c|c|c|c|}
\hline \multirow[t]{3}{*}{ System } & & \multicolumn{4}{|c|}{ Mean error (\%) } \\
\hline & & \multicolumn{2}{|c|}{ Std MPTA $^{a}$} & \multicolumn{2}{|c|}{ New MPTA ${ }^{b}$} \\
\hline & & $\mathrm{N}_{\mathrm{ex}}^{i}$ & Select & $\mathrm{N}_{\mathrm{ex}}^{i}$ & Select \\
\hline \multirow[t]{3}{*}{$\mathrm{CO}_{2} / \mathrm{N}_{2} 298 \mathrm{~K}$} & $\mathrm{CO}_{2}$ component & 2.08 & - & 2.36 & - \\
\hline & $\mathrm{N}_{2}$ component & 44.80 & 106.17 & 26.40 & 43.91 \\
\hline & Mixture & 2.09 & - & 1.21 & - \\
\hline \multirow[t]{3}{*}{$\mathrm{CO}_{2} / \mathrm{N}_{2} 318 \mathrm{~K}$} & $\mathrm{CO}_{2}$ component & 2.27 & - & 2.00 & - \\
\hline & $\mathrm{N}_{2}$ component & 28.35 & 50.85 & 19.79 & 26.24 \\
\hline & Mixture & 3.24 & - & 2.23 & - \\
\hline \multicolumn{2}{|c|}{ Overall mean error } & 13.48 & 74.90 & 8.87 & 33.92 \\
\hline \multicolumn{2}{|c|}{ Overall increased performance } & - & - & 34.20 & 54.71 \\
\hline
\end{tabular}

23 experimental data points

a Std MPTA mean pure fit error refers to the mean absolute deviation between experimentally measured excess adsorptions and those computed by (3) using (2) and (1)

b New MPTA mean pure fit error refers to the mean absolute deviation between experimentally measured excess adsorptions and those computed by (3) using (2) and (8) with individual $z_{0}^{i} \epsilon_{0}^{i}$ and $\beta^{i}$ parameters 
Table 15 Comparison of standard and new MPTA models on Zeolite-NaX at $323 \mathrm{~K}$ and $373 \mathrm{~K}$ under $1 \mathrm{Bar}$

\begin{tabular}{|c|c|c|c|c|c|}
\hline \multirow[t]{3}{*}{ System } & & \multicolumn{4}{|c|}{ Mean error (\%) } \\
\hline & & \multicolumn{2}{|c|}{ Std MPTA ${ }^{a}$} & \multicolumn{2}{|c|}{ New MPTA ${ }^{b}$} \\
\hline & & $\mathrm{N}_{\mathrm{ex}}^{i}$ & Select & $\mathrm{N}_{\mathrm{ex}}^{i}$ & Select \\
\hline \multirow[t]{3}{*}{$\mathrm{CO}_{2} / \mathrm{CO} 323 \mathrm{~K}$} & $\mathrm{CO}_{2}$ component & 22.33 & 43.22 & 24.51 & 36.82 \\
\hline & CO component & 26.22 & - & 19.47 & - \\
\hline & Mixture & 24.62 & - & 21.52 & - \\
\hline \multirow[t]{3}{*}{$\mathrm{CO}_{2} / \mathrm{CO} 373 \mathrm{~K}$} & $\mathrm{CO}_{2}$ component & 19.13 & 33.52 & 19.66 & 33.63 \\
\hline & CO component & 22.04 & - & 22.06 & - \\
\hline & Mixture & 16.39 & - & 16.80 & - \\
\hline \multicolumn{2}{|c|}{ Overall mean error } & 21.59 & 36.75 & 20.28 & 34.69 \\
\hline \multicolumn{2}{|c|}{ Overall increased performance } & - & - & 6.07 & 5.61 \\
\hline
\end{tabular}

Three experimental data points

${ }^{\text {a }}$ Std MPTA mean pure fit error refers to the mean absolute deviation between experimentally measured excess adsorptions and those computed by (3) using (2) and (1)

b New MPTA mean pure fit error refers to the mean absolute deviation between experimentally measured excess adsorptions and those computed by (3) using (2) and (8) with individual $z_{0}^{i}, \epsilon_{0}^{i}$ and $\beta^{i}$ parameters
Table 16 Comparison of standard and new MPTA models on $\mathrm{H}$-Mordenite at $303 \mathrm{~K}$ and pressure from 1 to $61 \mathrm{kPa}$

\begin{tabular}{|c|c|c|c|c|c|}
\hline \multirow[t]{3}{*}{ System } & & \multicolumn{4}{|c|}{ Mean error (\%) } \\
\hline & & \multicolumn{2}{|c|}{ Std MPTA ${ }^{a}$} & \multicolumn{2}{|c|}{ New MPTA ${ }^{b}$} \\
\hline & & $\mathrm{N}_{\mathrm{ex}}^{i}$ & Select & $\mathrm{N}_{\mathrm{ex}}^{i}$ & Select \\
\hline \multirow[t]{3}{*}{$\mathrm{CO}_{2} / \mathrm{H}_{2} \mathrm{~S}$} & $\mathrm{CO}_{2}$ component & 36.12 & - & 51.08 & - \\
\hline & $\mathrm{H}_{2} \mathrm{~S}$ component & 7.33 & 72.78 & 10.37 & 145.12 \\
\hline & Mixture & 6.32 & - & 2.20 & - \\
\hline \multirow[t]{3}{*}{$\mathrm{C}_{3} \mathrm{H}_{8} / \mathrm{CO}_{2}$} & $\begin{array}{l}\mathrm{C}_{3} \mathrm{H}_{8} \text { compo- } \\
\text { nent }\end{array}$ & 22.62 & 100.45 & 16.70 & 84.50 \\
\hline & $\mathrm{CO}_{2}$ component & 49.83 & - & 47.31 & - \\
\hline & Mixture & 16.85 & - & 21.76 & - \\
\hline \multirow[t]{3}{*}{$\mathrm{C}_{3} \mathrm{H}_{8} / \mathrm{H}_{2} \mathrm{~S}$} & $\begin{array}{l}\mathrm{C}_{3} \mathrm{H}_{8} \text { compo- } \\
\text { nent }\end{array}$ & 47.15 & - & 45.10 & - \\
\hline & $\mathrm{H}_{2} \mathrm{~S}$ component & 17.42 & $--^{c}$ & 15.93 & $--^{c}$ \\
\hline & Mixture & 20.42 & - & 20.12 & - \\
\hline \multirow[t]{4}{*}{$\mathrm{CO}_{2} / \mathrm{H}_{2} \mathrm{~S} / \mathrm{C}_{3} \mathrm{H}_{8}$} & $\mathrm{CO}_{2}$ component & 50.59 & - & 63.64 & - \\
\hline & $\mathrm{H}_{2} \mathrm{~S}$ component & 92.01 & $-^{c}$ & 100.81 & $-^{c}$ \\
\hline & $\begin{array}{l}\mathrm{C}_{3} \mathrm{H}_{8} \text { compo- } \\
\text { nent }\end{array}$ & 82.49 & $--^{c}$ & 83.15 & $-^{c}$ \\
\hline & Mixture & 29.42 & - & 31.45 & - \\
\hline \multicolumn{2}{|c|}{ Overall mean error } & 37.94 & 86.62 & 40.55 & 114.81 \\
\hline \multicolumn{2}{|c|}{ Overall increased performance } & - & - & -6.88 & -32.54 \\
\hline
\end{tabular}

36 experimental data points.

a Std MPTA mean pure fit error refers to the mean absolute deviation between experimentally measured excess adsorptions and those computed by (3) using (2) and (1)

b New MPTA mean pure fit error refers to the mean absolute deviation between experimentally measured excess adsorptions and those computed by (3) using (2) and (8) with individual $z_{0^{\prime}}^{i} \epsilon_{0}^{i}$ and $\beta^{i}$ parameters

c Error on selectivity over $100 \%$ due to large error on the least adsorbed component 
Table 17 MPTA adsorption accuracy for pure gases, binary, and ternary mixtures

\begin{tabular}{|c|c|c|c|c|}
\hline & Data & Std MPTA ${ }^{a}$ & New MPTA ${ }^{b}$ & $\begin{array}{l}\text { Perfor- } \\
\text { mance } \\
\text { increase }\end{array}$ \\
\hline Pure gases fit & 877 & $4.71 \%$ & $2.38 \%$ & $49.5 \%$ \\
\hline Total binary mixture & 438 & $5.79 \%$ & $5.93 \%$ & $-2.4 \%$ \\
\hline Binary components & 876 & $17.01 \%$ & $15.77 \%$ & $7.3 \%$ \\
\hline Total ternary mixture & 72 & $14.45 \%$ & $13.32 \%$ & $7.8 \%$ \\
\hline \multirow[t]{2}{*}{ Ternary components } & 216 & $34.94 \%$ & $34.46 \%$ & $1.4 \%$ \\
\hline & 2479 & $12.16 \%$ & $10.85 \%$ & $10.8 \%$ \\
\hline
\end{tabular}

a Std MPTA mean pure fit error refers to the mean absolute deviation between experimentally measured excess adsorptions and those computed by (3) using (2) and (1)

${ }^{b}$ New MPTA mean pure fit error refers to the mean absolute deviation between experimentally measured excess adsorptions and those computed by (3) using (2) and (8) with individual $z_{0^{\prime}}^{i} \varepsilon_{0}^{i}$ and $\beta^{i}$ parameters

Table 18 MPTA adsorption accuracy for binary prediction breakdown by adsorbent species

\begin{tabular}{lllll}
\hline & Data & Std MPTA $^{\text {a }}$ & New MPTA & $\begin{array}{l}\text { Perfor- } \\
\text { mance } \\
\text { increase }\end{array}$ \\
\hline AC total mixture & 264 & $5.12 \%$ & $5.67 \%$ & $-9.7 \%$ \\
AC components & 528 & $17.79 \%$ & $16.86 \%$ & $5.2 \%$ \\
MOF total mixture & 18 & $5.99 \%$ & $5.12 \%$ & $14.5 \%$ \\
MOF components & 36 & $14.33 \%$ & $11.34 \%$ & $20.9 \%$ \\
Zeolite total mixture & 156 & $6.89 \%$ & $6.46 \%$ & $6.2 \%$ \\
Zeolite components & 312 & $16.01 \%$ & $14.44 \%$ & $9.8 \%$ \\
& 1314 & $13.27 \%$ & $12.49 \%$ & $5.9 \%$ \\
\hline
\end{tabular}

a Std MPTA mean pure fit error refers to the mean absolute deviation between experimentally measured excess adsorptions and those computed by (3) using (2) and (1)

b New MPTA mean pure fit error refers to the mean absolute deviation between experimentally measured excess adsorptions and those computed by (3) using (2) and (8) with individual $z_{0}^{i}, \epsilon_{0}^{i}$ and $\beta^{i}$ parameters
Table 19 Comparison of the fitting parameters for $\mathrm{N}_{2} / \mathrm{CO}_{2}$ mixture on AC, MOF, and zeolite

\begin{tabular}{|c|c|c|c|c|c|}
\hline Model & Gas & Parameter & AC F-400 & MOF-5 & $\begin{array}{l}\text { Zeolite } \\
\text { ZSM-5 }\end{array}$ \\
\hline \multirow[t]{6}{*}{ New MPTA ${ }^{b}$} & \multirow[t]{3}{*}{$\mathrm{N}_{2}$} & $z_{0}^{i}\left(\mathrm{~cm}^{3} / \mathrm{g}\right)$ & 0.245 & 1.13 & 0.125 \\
\hline & & $\varepsilon_{0}^{i}(\mathrm{~J} / \mathrm{mol})$ & 7289 & 2744 & 7310 \\
\hline & & $\beta^{i}$ & 2.32 & 1.39 & 2.10 \\
\hline & \multirow[t]{3}{*}{$\mathrm{CO}_{2}$} & $z_{0}^{i}\left(\mathrm{~cm}^{3} / \mathrm{g}\right)$ & 0.306 & 2.76 & 0.09 \\
\hline & & $\varepsilon_{0}^{i}(\mathrm{~J} / \mathrm{mol})$ & 7637 & 1945 & 11568 \\
\hline & & $\beta^{i}$ & 1.86 & 1.00 & 2.42 \\
\hline \multirow[t]{4}{*}{ Std MPTA } & \multirow[t]{4}{*}{$\mathrm{N}_{2} / \mathrm{CO}_{2}$} & $z_{0}\left(\mathrm{~cm}^{3} / \mathrm{g}\right)$ & 0.307 & 1.75 & 0.09 \\
\hline & & $\varepsilon_{0}^{N_{2}}(\mathrm{~J} / \mathrm{mol})$ & 5929 & 1893 & 8525 \\
\hline & & $\varepsilon_{0}^{\mathrm{CO}_{2}}(\mathrm{~J} / \mathrm{mol})$ & 7768 & 2826 & 11585 \\
\hline & & $\beta$ & 1.70 & 1.25 & 2.44 \\
\hline $\mathrm{T}$ & & $(\mathrm{K})$ & 318.2 & 297 & 318 \\
\hline BET & & $\left(\mathrm{m}^{2} / \mathrm{g}\right)$ & 850 & 3054 & 288 \\
\hline $\begin{array}{l}\text { micro- } \\
\text { volume }\end{array}$ & & $\left(\mathrm{cm}^{3} / \mathrm{g}\right)$ & 0.495 & 1.31 & 0.155 \\
\hline
\end{tabular}

a Std MPTA mean pure fit error refers to the mean absolute deviation between experimentally measured excess adsorptions and those computed by (3) using (2) and (1)

b New MPTA mean pure fit error refers to the mean absolute deviation between experimentally measured excess adsorptions and those computed by (3) using (2) and (8) with individual $z_{0}^{i}, \epsilon_{0}^{i}$ and $\beta^{i}$ parameters

Table 20 Comparison of the fitting parameters for $\mathrm{CH}_{4} / \mathrm{N}_{2}$ mixture on $\mathrm{AC}, \mathrm{MOF}$, and zeolite

\begin{tabular}{llllll}
\hline Model & Gas & Parameter & $\begin{array}{l}\text { AC Norit- } \\
\text { R1 }\end{array}$ & MOF-5 & Zeolite 13X \\
& & & & \\
\hline New & $\mathrm{CH}_{4}$ & $z_{0}^{i}\left(\mathrm{~cm}^{3} / \mathrm{g}\right)$ & 0.385 & 1.29 & 0.245 \\
MPTA $^{\mathrm{b}}$ & & $\varepsilon_{0}^{i}(\mathrm{~J} / \mathrm{mol})$ & 8095 & 3511 & 8479 \\
& & $\beta^{i}$ & 1.94 & 1.44 & 2.90 \\
& $\mathrm{~N}_{2}$ & $z_{0}^{i}\left(\mathrm{~cm}^{3} / \mathrm{g}\right)$ & 0.311 & 1.13 & 3.74 \\
& & $\varepsilon_{0}^{i}\left(\mathrm{~J} / \mathrm{mol}^{2}\right)$ & 7273 & 2744 & 573 \\
& & $\beta^{i}$ & 2.31 & 1.39 & 0.58 \\
& & $z_{0}\left(\mathrm{~cm}^{3} / \mathrm{g}\right)$ & 0.386 & 1.25 & 0.26 \\
Std MPTA & $\mathrm{CH}_{4} / \mathrm{N}_{2}$ & $\mathrm{CH}_{4}(\mathrm{~J} /$ & 8085 & 3580 & 8238 \\
& & $\mathrm{~mol}^{2}$ & & & \\
& & $\varepsilon_{0}^{N_{2}}(\mathrm{~J} / \mathrm{mol})$ & 6141 & 2558 & 7223 \\
& & $\beta$ & 1.88 & 1.45 & 2.68 \\
T & & $(\mathrm{K})$ & 297 & 297 & 303 \\
BET & & $\left(\mathrm{m}^{2} / \mathrm{g}\right)$ & 1407 & 3054 & 164 \\
micro- & & $\left(\mathrm{cm}^{3} / \mathrm{g}\right)$ & 0.351 & 1.31 & 0.21 \\
volume & & & & & \\
\hline
\end{tabular}

a Std MPTA mean pure fit error refers to the mean absolute deviation between experimentally measured excess adsorptions and those computed by (3) using (2) and (1)

b New MPTA mean pure fit error refers to the mean absolute deviation between experimentally measured excess adsorptions and those computed by (3) using (2) and (8) with individual $z_{0}^{i} \epsilon_{0}^{i}$ and $\beta^{i}$ parameters 


\section{Conclusion}

A new approach to the Multicomponent Potential Theory of Adsorption was presented in which individual fitting parameters replaced the commons ones. Specifically, the new approach uses distinct values of the parameters $z_{0}$ (the limiting microporous volume) and $\beta$ (the heterogeneity parameter) for the model pure gases fits. In the standard MPTA model, those parameters are shared by all the pure gases, which generated the coupling of pure gases. In this new formulation, there are individual parameters for each pure gases considered. This implies more fitting parameters ( $3 M$ parameters instead of $M+2$ ) but is nevertheless easier to understand and adjust because the model decomposed into $M$ individual three parameters fit. The objective pursued is the ability to predict mixture adsorption without any experimental measurements by extrapolating parameters from one adsorbent to another. Under that scope, the independence of the components is a crucial step.

After testing over 500 experimental mixture data, the new approach performed $4.67 \%$ better than the usual model, which gives a mean error of $6.97 \%$ for total mixture excess adsorption, and an overall mean error of $15.30 \%$ if the component and total mixture adsorption are combined.

The best performance of the new MPTA model on binary mixture was achieved on MOF with a combined accuracy (component plus total mixture accuracy) of $9.27 \%$, followed by Zeolite with an $11.78 \%$ accuracy, and finally activated carbon with an accuracy of $13.13 \%$.

For the vast majority of cases, the new MPTA approach gives a better accuracy compared to the standard MPTA model. The only situations where standard MPTA performs better than the new model are for activated carbon total mixture adsorption and total binary mixture adsorption. However, the new MPTA model does perform better for activated carbon component adsorption and binary mixture component adsorption. As mention earlier, the most relevant prediction for multicomponent adsorption is the individual component adsorption. Overall, the component adsorption predictions of the new MPTA model are more accurate than the standard MPTA model, which justifies using the new MPTA model described in this paper.

Preprint of this paper can also be found at https://arxiv .org/abs/1911.01293.

Acknowledgements The authors would like to thank Professor Jacques Goyette for useful discussions, the Natural Sciences and Engineering Research Council of Canada, and the Savannah River National Laboratory for financial support.

\section{Compliance with ethical standards}

Conflict of interest The authors declare that they have no conflict of interest.

\section{References}

1. Sudibandriyo $M$, Pan $Z$, Fitzgerald JE, Robinson RL, Gasem KA (2003) Adsorption of methane, nitrogen, carbon dioxide, and their binary mixtures on dry activated carbon at $318.2 \mathrm{~K}$ and pressures up to $13.6 \mathrm{MPa}$. Langmuir 19(13):5323. https://doi. org/10.1021/la020976k

2. Dreisbach F, Staudt R, Keller JU (1999) High pressure adsorption data of methane, nitrogen, carbon dioxide and their binary and ternary mixtures on activated carbon. Adsorption 5(3):215. https ://doi.org/10.1023/A:1008914703884

3. Schell J, Casas N, Pini R, Mazzotti M (2012) Pure and binary adsorption of $\mathrm{CO} 2, \mathrm{H} 2$, and $\mathrm{N} 2$ on activated carbon. Adsorption 18(1):49. https://doi.org/10.1007/s10450-011-9382-y

4. He Y, Yun JH, Seaton NA (2004) Adsorption equilibrium of binary methane/ethane mixtures in BPL activated carbon: isotherms and calorimetric heats of adsorption. Langmuir 20(16):6668

5. Kloutse F, Hourri A, Natarajan S, Benard P, Chahine R (2018) Experimental benchmark data of $\mathrm{CH} 4, \mathrm{CO} 2$ and $\mathrm{N} 2$ binary and ternary mixtures adsorption on MOF-5. Sep Purif Technol 197:228. https://doi.org/10.1016/j.seppur.2018.01.013

6. Kloutse F, Hourri A, Natarajan S, Benard P, Chahine R (2018) Hydrogen separation by adsorption: experiments and modelling of $\mathrm{H} 2-\mathrm{N} 2-\mathrm{CO} 2$ and $\mathrm{H} 2-\mathrm{CH} 4-\mathrm{CO} 2$ mixtures adsorption on CuBTC and MOF-5. Microporous Mesoporous Mater 271:175

7. Grande CA, Gigola C, Rodrigues AE (2003) Propane-propylene binary adsorption on zeolite 4A. Adsorption 9(4):321

8. Talu O, Li J, Kumar R, Mathias PM, Moyer JD Jr, Schork JM (1996) Measurement and analysis of oxygen/nitrogen/5A-zeolite adsorption equilibria for air separation. Gas Sep Purif 10(3):149

9. Bakhtyari A, Mofarahi M (2014) Pure and binary adsorption equilibria of methane and nitrogen on zeolite 5A. J Chem Eng Data 59(3):626

10. Mofarahi M, Bakhtyari A (2015) Experimental investigation and thermodynamic modeling of $\mathrm{CH} 4 / \mathrm{N} 2$ adsorption on zeolite $13 \mathrm{X}$. J Chem Eng Data 60(3):683

11. Hefti M, Marx D, Joss L, Mazzotti M (2015) Adsorption equilibrium of binary mixtures of carbon dioxide and nitrogen on zeolites ZSM-5 and 13X. Microporous Mesoporous Mater 215:215

12. Belmabkhout $Y$, Pirngruber $G$, Jolimaitre $E$, Methivier A (2007) A complete experimental approach for synthesis gas separation studies using static gravimetric and column breakthrough experiments. Adsorption 13(3-4):341

13. Talu O, Zwiebel I (1986) Multicomponent adsorption equilibria of nonideal mixtures. AIChE J 32(8):1263

14. Shapiro AA, Stenby EH (1998) Potential theory of multicomponent adsorption. J Colloid Interface Sci 201(2):146. https://doi. org/10.1006/jcis.1998.5424

15. Polanyi M (1963) The potential theory of adsorption. Science 141(3585):1010. https://doi.org/10.1126/science.141.3585.1010

16. Monsalvo M, Shapiro A (2007) Modeling adsorption of binary and ternary mixtures on microporous media. Fluid Phase Equilibria 254(1-2):91. https://doi.org/10.1016/j.fluid.2007.02.006

17. Monsalvo M, Shapiro A (2007) Prediction of adsorption from liquid mixtures in microporous media by the potential theory. Fluid Phase Equilibria 261(1-2):292. https://doi.org/10.1016/j. fluid.2007.07.067 
18. Monsalvo MA, Shapiro AA (2009) Modeling adsorption of liquid mixtures on porous materials. J Colloid Interface Sci 333(1):310

19. Dubinin MM (1989) Fundamentals of the theory of adsorption in micropores of carbon adsorbents: characteristics of their adsorption properties and microporous structures. Pure Appl Chem 61(11):1841. https://doi.org/10.1351/pac198961111841

20. Dundar E, Zacharia R, Chahine R, Bénard P (2014) Potential theory for prediction of high-pressure gas mixture adsorption on activated carbon and MOFs. Sep Purif Technol 135:229. https:// doi.org/10.1016/j.seppur.2014.08.021

21. Dundar E, Zacharia R, Chahine R, Bénard P (2014) Performance comparison of adsorption isotherm models for supercritical hydrogen sorption on MOFs. Fluid Phase Equilibria 363:74. https ://doi.org/10.1016/j.fluid.2013.11.029

22. Stoeckli F (1998) Recent developments in Dubinin's theory. Carbon 36(4):363

23. Terzyk AP, Gauden PA, Kowalczyk P (2002) What kind of pore size distribution is assumed in the Dubinin-Astakhov adsorption isotherm equation? Carbon 40(15):2879

24. Gervais Lavoie R, Ouellet M, Hamelin J, Bénard P (2018) Numerical implementation of the multicomponent potential theory of adsorption in Python using the NIST Refprop database. Commun Comput Phys 23(5):1602. https://doi.org/10.4208/cicp. OA-2017-0012arXiv:1702.05401

25. Myers A (2002) Thermodynamics of adsorption in porous materials. AIChE J 48(1):145. https://doi.org/10.1002/aic.690480115

26. Lemmon E, Huber M, McLinden M (2013) NIST standard reference database 23: reference fluid thermodynamic and transport properties-REFPROP, version 9.1. National Institute of Standards and Technology, Standard Reference Data Program, Gaithersburg

27. Newville $M$, Stensitzki T, Allen DB, Rawlik M, Ingargiola A, Nelson A (2016) LMFIT: non-linear least-square minimization and curvefitting for Python. Astrophysics Source Code Library

28. Naseri AA, Dehghani MR, Behzadi B (2014) Modeling adsorption in binary associating solvents using the extended MPTA model. Adsorption 20(4):555
29. Bjørner MG, Shapiro AA, Kontogeorgis GM (2013) Potential theory of adsorption for associating mixtures: possibilities and limitations. Ind Eng Chem Res 52(7):2672. https://doi.org/10.1021/ ie302144t

30. Bartholdy S, Bjørner MG, Solbraa E, Shapiro A, Kontogeorgis GM (2013) Capabilities and limitations of predictive engineering theories for multicomponent adsorption. Ind Eng Chem Res 52(33): 11552

31. Nesterov I, Shapiro A, Kontogeorgis GM (2015) Multicomponent adsorption model for polar and associating mixtures. Ind Eng Chem Res 54(11):3039

32. Russell BP, Levan MD (1994) Pore size distribution of BPL activated carbon determined by different methods. Carbon 32(5):845

33. Sowunmi AR, Folayan CO, Anafi FO, Ajayi OA, Omisanya NO, Obada DO, Dodoo-Arhin D (2018) Dataset on the comparison of synthesized and commercial zeolites for potential solar adsorption refrigerating system. Data $\mathrm{Br}$ 20:90-95

34. LiY, Guan HM, Chung TS, Kulprathipanja S (2006) Effects of novel silane modification of zeolite surface on polymer chain rigidification and partial pore blockage in polyethersulfone (PES)zeolite A mixed matrix membranes. J Membr Sci 275(1-2):17

35. Zhang Z, Zhang W, Chen X, Xia Q, Li Z (2010) Adsorption of CO2 on zeolite $13 \mathrm{X}$ and activated carbon with higher surface area. Sep Sci Technol 45(5):710

36. Sang S, Chang F, Liu Z, He C, He Y, Xu L (2004) Difference of ZSM-5 zeolites synthesized with various templates. Catal Today 93:729

37. Sagert N, Pouteau R, Bailey M, Sargent F (1972) Benzene radical cation formation on hydrogen mordenite. The role of adsorbed oxygen. Can J Chem 50(13):2041

Publisher's Note Springer Nature remains neutral with regard to jurisdictional claims in published maps and institutional affiliations. 